\title{
Capacity for Forestry Research in Selected Countries of West and Central Africa
}

M.J. Spilsbury, G.S. Kowero and F. Tchala-Abina

CENTER FOR INTERNATIONAL FORESTRY RESEARCH

Office address: Jalan CIFOR, Situ Gede, Sindang Barang, Bogor 16680, Indonesia Mailing address: P.O. Box 6596 JKPWB, Jakarta 10065, Indonesia

Tel.: +62 (251) 622622; Fax: +62 (251) 622100

E-mail: cifor@cgiar.org

Website: http://www.cgiar.org/cifor 


\section{Table of Contents}

List of Abbreviations $i$

Acknowledgements iv

Executive Summary 1

1. Introduction 1

2. Current Status of Forestry Research 2

2.1 Previous forestry capacity-related work in West and Central Africa 3

3. Methodology 3

3.1 Countries and institutions included in the survey 4

3.2 Limitations of study methodology 4

4. Results and Discussion 5

4.1 Resources 6

4.1.1 Human resources 6

4.1.2 Financial resources 8

4.1.3 Research support facilities 9

4.2 Research environment 10

4.2.1 External research environment 10

4.2.2 Internal research environment 13

4.3 Published output 15

4.4 Strengths, weaknesses, opportunities and threats $\quad 15$

4.4.1 Strengths and weaknesses $\quad 16$

4.4.2 Opportunities and threats 16

5. Conclusions and Recommendations 16

5.1 Conclusions 16

5.1.1 Human resources 16

5.1.2 Financial resources 16

5.1.3 Adequacy of research capacity to support

5.1.4 Linkage between the research institutions
and other relevant institutions

5.1.5 Adequacy of resources to support research $\quad 17$

5.1.6 Main constraints to research and capacity building 17

5.2 Recommendations 17

6. References 19

Annexes $\quad 21$

Annex 1. Indicator Values for Research Capacity in West and Central Africa 21

Annex 2. Methodology and Indicators of Research Capacity 22

Annex 3. Research Capacity Profiles by Institution 27

Annex 4. Research Capacity Indicators Across Institutions 31

Annex 5. 'SWOT' Analysis of Forestry Research Institutions in the West and Central African Region 34

Annex 6. Some Positive and Negative Aspects of Regional Approaches to Research Coordination 37 


\section{List of Tables:}

Table 1. Summary data on forestry research capacity

Table 2. A summary of research capacity indicators used in the study

Table 3. Institutions surveyed, and others known to be involved in forestry-related research in West and Central Africa

Table 4. Human resources from the survey sample aggregated by country

Table 5a. Distribution of support staff by institution 7

Table 5b. Research support indicator values

Table 6. Percentage of total reported budget allocated to salaries

Table 7. Summary of research support facilities

Table 8. Research interactions by institution and their perceived value

Table 9. Educational interactions and their perceived value

Table 10. Budget and staff time allocated to interactions with research user groups

Table 11. Internal interactions - indicator values, meeting types, frequency of meetings and perceived benefits

Table 12. Salary incentives - income relative to similar professionals employed in the same country

Table 13. Research outputs by institution for the period 1993-1996

\section{List of Figures:}

Figure 1. Distribution of scientific staff by institute

Figure 2. Gender balance of research staff by institute 


\section{List of Abbreviations}

\section{General}

\begin{tabular}{|c|c|}
\hline ANR & Agriculture and Natural Resources \\
\hline ARIs & Advanced Research Institutes \\
\hline CORAF & Conférence de Responsables de Recherche Agronomique Africains. \\
\hline CIFOR & Centre for International Forestry Research \\
\hline FORIG & Forestry Research Institute of Ghana \\
\hline FORIN & Forestry Research Institute of Nigeria \\
\hline FORNESSA & Forestry Research Network for Sub-Saharan Africa \\
\hline IARCs & International Agricultural Research Centres \\
\hline IDEFOR/DFO & Institut des Forêts de Côte d'Ivoire/Département des Forêts \\
\hline IRAD & $\begin{array}{l}\text { Institut de Recherche Agronomique pour le Développement/Secteur } \\
\text { Environnement et Forêt }\end{array}$ \\
\hline IRET & Institut de Recherche en Ecologie Tropicale, Gabon \\
\hline IRNR & $\begin{array}{l}\text { Institute of Renewable Natural Resources, Department of Silviculture and } \\
\text { Forest Management, University of Science \& Technology, Kumasi, Ghana }\end{array}$ \\
\hline LAN & Local Area Network \\
\hline NARS & National Agricultural Research Systems \\
\hline NGO & Non-governmental Organisation \\
\hline SPAAR & Special Program for African Agricultural Research \\
\hline SSA & Sub-Saharan Africa \\
\hline
\end{tabular}

\section{Related to tables, figures and annexes}

URF Unité de Recherche Forestière, Institut de Recherche Agronomique du Bénin

IRAD Institut de Recherche Agronomique pour le Développement/Secteur Environnement et Forét

DSCHANG Department of Forestry, Faculty of Agronomy, University of Dschang,

FORIG Forestry Research Institute of Ghana

FORIN Forestry Research Institute of Nigeria

IRET Institut de Recherche en Ecologie Tropicale, Gabon

IRNR Institute of Renewable Natural Resource, Department. of Silviculture and Forest Management, University of Science \& Technology, Kumasi, Ghana

IDEFOR/DFO Institut des Forêts de Côte d'Ivoire/Département des Forêts

UIBAD Department of Forest Resources Management, University of Ibadan, Nigeria 


\section{Acknowledgements}

This study was undertaken in seven countries in West and Central Africa and a total of ten institutions were surveyed. The authors wish to thank the institutions and the many scientists who generously supplied the data for this work.

The Institute of Environmental Studies, University of Zimbabwe, is also acknowledged for providing support facilities during the preparation of this report. 


\title{
Capacity for Forestry Research in Selected Countries of West and Central Africa
}

\author{
M.J. Spilsbury ${ }^{1}$, G.S. Kowero ${ }^{1}$ and F. Tchala-Abina ${ }^{2}$
}

\begin{abstract}
Executive Summary
In 1997/98 a survey of nine forestry institutions in the West and Central African countries of Nigeria, Ghana, Côte d'Ivoire, Cameroon, Gabon and Benin was conducted. The survey methodology utilises ten indicators of research capacity that facilitate comparisons across the survey sample. General trends relating to research capacity in the region are highlighted and include: insufficient collaborative research; poor linkages between research, education and development; inadequate flow of information and access to scientific literature; and a low level of sustainability for research programme support.

While there is still a considerable need to invest in the development of human resources and physical infrastructure at the institutional level, governments and development assistance agencies should pay more attention to promoting efficiency and effectiveness of the 'supply' side of research systems (national and regional). There have been few consistent attempts to develop mechanisms to match research 'supply'to the real 'demands' in terms of providing solutions to the most pressing problems.
\end{abstract}

\section{Introduction}

In 1997/98 a survey of nine forestry institutions in the West and Central African countries of Nigeria, Ghana, Côte d'Ivoire, Cameroon, Gabon and Benin was conducted. The Central African Republic was also visited but the institution charged with the mandate for forestry research, Institut Centralafricain de la Recherché Agronomique (ICRA), has yet to initiate an operational research programme. The political situation in both Republique du Congo and Republique Democratique du Congo prevented investigation in these two countries. The survey involved the collection, processing and analysis of reliable and comprehensive data on National Research Systems (NARS) for forestry-related research in order to identify and report on major trends and emerging policy issues with regard to the development of NARS. Specifically, the goals of the study were to:

- examine adequacy of current forestry-related research capacity to support decisions on resource policy;

- examine the linkages between forestry-related research institutions, and identify opportunities for enhanced collaboration;

- evaluate the adequacy of research-supporting resources and infrastructure; and

- identify major constraints to, and opportunities for, development of forestry-related research capacity.

In all its operational areas, CIFOR addresses its research agenda through a variety of collaborative arrangements with partners in many countries in the developing tropics. Collaborative partnerships range from public and private institutions to NGOs and individuals. This strategy seeks research-based solutions to problems of mutual interest and priority but also aims to achieve 'capacity building through the research process' in NARS. Therefore structured, comparative, baseline information documenting the current available research capacity in CIFOR's geographical priority areas, including our major partners in the region, is a prerequisite for improving decisions about the establishment of new partnerships. It also assists us to meet demands for accountability and transparency in justifying such decisions and assess changes in research capacity over time.

In 1995/96 CIFOR conducted a forestry research capacity assessment covering the Southern African Development Community (SADC) region. The present survey, the second in a series of similar exercises planned by CIFOR, focuses on West and Central Africa. The study builds on the methodology used for the SADC study (Kowero and Spilsbury 1997a,b). Sufficient details are provided for the document to 'stand-alone' and not require the reader to refer to the earlier publication. In this study, forest

${ }^{1}$ CIFOR, P.O. Box 6596, JKPWB, Jakarta 10065, Indonesia.

2 Sécrétaire Permanent de I' Environnement, BP 12489, Yaounde, Cameroon. 
research capacity was again defined as 'the extent/degree to which a research institution is capable of effectively directing its resources towards the resolution of forestryrelated research problems'.

The level of output of a research institution should provide a measure of its capacity. Most commonly such output is reflected by the publications of the institution. However, publications as a measure of output indicate previous productivity and not necessarily current potential or even achievements with respect to the common goal of forestry research - to solve problems (Kowero and Spilsbury 1997a,b).

This study goes beyond an examination of institution's reported results and an account of its resources, to a more detailed examination of how institutions deploy resources in the research environment. The efficiency with which an institution interacts with its work environment is indicative of its capacity to advance its research agenda within the limitations imposed by its environment.

\section{Current Status of Forestry Research}

Investment in forestry research and the extent of the human resource available to conduct research in developing countries is low in comparison to the agricultural sector and in comparison to the value of goods and services derived from forests. Pardey et al. (1991), however, assert that 'comparison...between the share of crop research in agricultural research and crop production's share of value-added in agriculture (AgGDP).... [indicates] that forestry research absorbs a larger share of research capacity than agriculture' However, this analysis ignores the fact that a large proportion of research effort in forestry is not directed towards outputs or outcomes that can be readily captured by crude aggregated indicators such as AgGDP, nor does AgGDP capture the many and varied 'non-tradeable' goods and services provided by forests. In addition, the number of forestry researchers active in research areas that have a direct 'commodity orientation' in developing countries would be only a subset of the total, perhaps less than $50 \%$ of the research cadre. (Spilsbury and Byron 1996; TAC 1997).

Expenditure on forestry research in developing countries in 1981 amounted to US\$ 186 million, of which 60\% was allocated to Asia, $21 \%$ to Sub-Saharan Africa and $19 \%$ to Latin America and the Caribbean (Mergen et al. 1988). More recent data are not available but, if past trends are an indication, current annual expenditures may be in excess of US\$200 million.

Developing countries account for only $12 \%$ of total investment in forestry research world-wide. Forestry research intensity in developing countries is considerably less than one-tenth of agricultural research intensity. Forest research expenditures as a percentage of the value of production have been estimated at 0.019 for low-income developing countries, 0.059 for middle-income developing countries and 0.070 for semiindustrialized countries. The corresponding ratios for agricultural research expenditures were estimated at $0.451,0.863$ and 0.816 respectively (Mergen et al. 1988) (TAC 1994).

Current statistics that attempt to capture the number of forestry research institutes and qualified researchers within them are available. FAO (1995) surveyed a total of 764 forestry research organisations in 112 countries, $7 \%$ of which were located in Sub-Saharan Africa, 3.8\% in West Asia-North Africa, 13.4\% in Asia Pacific and 14.7\% in Latin America and the Caribbean (Table 1). Human resources, in terms of graduate staff in these institutions, do not follow the same pattern. More researchers, $25 \%$ of the global total, are located in the Asia Pacific developing countries. In Sub-Saharan Africa, universities represent only $14 \%$ of the forestry-related research institutes. The figures for West Asia-North Africa, Asia-Pacific and Latin America-Caribbean are $10.3 \%, 20.5 \%$ and $31.3 \%$ respectively.

Table 1. Summary data on forestry research capacity.

\begin{tabular}{lccrr}
\hline REGION & $\begin{array}{c}\text { Forestry } \\
\text { research } \\
\text { institutes (\%) }\end{array}$ & $\begin{array}{c}\mathrm{N}^{\circ} \text { of } \\
\text { research } \\
\text { institutes }\end{array}$ & $\begin{array}{r}\text { Graduate } \\
\text { researchers (\%) } \\
(1985 \text { values) }\end{array}$ & \multicolumn{1}{c}{$\begin{array}{c}\mathrm{N}^{\circ} \text { of } \\
\text { researchers }\end{array}$} \\
\hline Sub-Saharan Africa & 7.0 & 54 & $4.0(7.3)$ & 1106 \\
West Asia-North Africa & 3.8 & 29 & $2.9(5.7)$ & 815 \\
Asia-Pacific (excl. China) & 13.4 & 102 & $25.8(9.4)$ & 7177 \\
Latin America-Caribbean & 14.7 & 112 & $9.7(5.4)$ & 2687 \\
GLOBAL TOTALS & 100 & 764 & 100 & 11785 \\
\hline
\end{tabular}

* = Pardey et al. (1991). Figures for Asia-Pacific exclude China.

Source: adapted from FAO (1995). 


\subsection{Previous forestry capacity-related work in West and Central Africa}

There are numerous reviews, surveys and other types of documentation that touch on forestry research capacity in the region in a much broader context. Kio (1990) presents an historical perspective on the evolution of forestry research in the region. Research infrastructure, he argues, has to a large degree been shaped by former colonial administrations. Before political independence, the forestry sector was dominated by export-oriented policies and the research agenda reflected the importance of the few desirable species with a narrow research focus on forest management and silviculture. "Almost without exception, the foundations of forest research were laid by the metropolitan powers and the mandates were largely determined by a strong European bias both in procedure for management and in anticipated products"(Kio 1990).

Someshwar (1994) reports on efforts by the World Bank in building forestry capacity in Sub-Saharan Africa based on its projects in the region. The study views forestry capacity in totality and makes no distinction between capacity for research and that for developmental forestry work. Odera and Pape (1994) review a programme to support forestry research in Sub-Saharan Africa with the overall aim of building capacity for forestry research. The African Academy of Sciences (1994) relates its experience in building research capacity in Africa and makes recommendations on how this may be strengthened. Ridker (1994) presents an analysis of the experiences of the World Bank in human resources development in SubSaharan Africa, identifying where the Bank faltered and how improvements can be made.

Jaycox (1993) emphasises the crucial role of human and institutional capacity in the development of Africa. The African Development Bank (1994) notes that Africa has the weakest institutional capacity for successfully implementing sustainable forestry development programmes. Similarly, the World Bank strategy for lending to the forestry sector in SSA focuses on four key areas: promotion of policy reforms; support to capacity building and human resource development; support to investments in critical areas; and promotion of better donor coordination in the forestry sector (Sharma et al. 1994).

Gilbert et al. (1994) give an account of problems facing agricultural research systems in the small countries of West Africa emphasising the inevitable requirement for many African research institutions to enhance capacity through collaboration in research. Walton (1994) suggests that the research areas able to lend themselves to regional collaborative approaches are: natural resource management; environmental issues, pests and diseases; and basic foods, methodologies, training; in addition to information on regional problems. He further notes that higher priority is given to natural resource management and environmental problems and that the issues involved favour regional approaches since they are complex, often cut across national boundaries, and require international cooperation if they are to be resolved. In this connection he identifies the following as the main reasons for a regional approach to research:

- to exchange information and combine the collective experience of professionals in the same field;

- to achieve economies of scale and efficiency by concentrating scarce human, financial, and other resources on key national and regional problems;

- to minimise duplication;

- to capture the effects of research spillover;

- to rationalise human resource development; and

- to mobilise research efforts on trans-national problems that require collaboration between countries (Walton 1994; and see Annex 6).

This largely parallels the approach advocated by the World Bank in launching the SPAAR in 1985, which considered the development of agricultural research in SSA in the context of regional frameworks and broaderbased research capacity development needs. It emphasised the following principles/concepts (World Bank 1996a):

- institutionalising a participatory and responsive strategic planning process;

- developing sustainable funding plans and mechanisms;

- improving institutional, human resource and management capacity;

- building country coalitions and support groups of stakeholders;

- strengthening linkages between research, extension, universities, the private sector, non-governmental organisations (NGOs), farmers and market agents in order to refocus the research agenda on constraints, both on- and off-farm; and

- promoting regional and international collaboration, to ensure cost effectiveness.

These ideas have been promoted in recent years by many bilateral and multilateral donor-funded initiatives, e.g., the Capacity Development and Utilisation Initiative in Ghana (World Bank 1996b). Therefore, capacity assessments must respond to these trends and attempt to capture the extent to which research institutes are implementing these ideas.

\section{Methodology}

The previous CIFOR study conducted by Kowero and Spilsbury $(1997 a, b)$ reviewed the literature relating to research capacity assessments and developed a revised methodology largely based on the earlier work of 
Bengston et al. (1988). The approach used in the present study builds on previous analyses by incremental improvement to existing indicators and the introduction of additional indicators of research capacity. The approach is based on the analysis of indicators within the institutions' external and internal environments which, we argue, are closely related to research capacity. Additionally, research support and research output was evaluated within the institutions. The study examined current and recent evolution of research capacity in national institutions but the research capacity existing in international organisations based in the region was deliberately excluded. The method uses a set of indicators described in detail in Annex 2 and summarised in Table 2.

Table 2. A summary of research capacity indicators used in the study.

\begin{tabular}{|c|c|}
\hline INDICATOR & SUMMARY DESCRIPTION \\
\hline $\begin{array}{l}\text { Human } \\
\text { Resources (HR) }\end{array}$ & $\begin{array}{l}\text { Captures numbers of staff, their } \\
\text { qualifications and experience. }\end{array}$ \\
\hline Technical Support & $\begin{array}{l}\text { Ratio of technical support staff to } \\
\text { research staff. }\end{array}$ \\
\hline Published Output & $\begin{array}{l}\text { A weighted ratio of publications per } \\
\text { researcher. }\end{array}$ \\
\hline \multicolumn{2}{|c|}{ EXTERNAL ENVIRONMENT } \\
\hline $\begin{array}{l}\text { Research } \\
\text { Interactions (RI) }\end{array}$ & $\begin{array}{l}\text { Frequency and benefit derived from } \\
\text { interactions with institutes in own } \\
\text { country, in the region, and elsewhere. }\end{array}$ \\
\hline $\begin{array}{l}\text { Educational } \\
\text { Interactions (EI) }\end{array}$ & $\begin{array}{l}\text { Frequency and benefit derived from } \\
\text { interactions with institutes in own } \\
\text { country, in the region, and elsewhere. }\end{array}$ \\
\hline $\begin{array}{l}\text { User } \\
\text { Interactions (UI) }\end{array}$ & $\begin{array}{l}\text { Staff time and budget allocated to } \\
\text { interactions with research user } \\
\text { groups. }\end{array}$ \\
\hline \multicolumn{2}{|c|}{ INTERNAL ENVIRONMENT } \\
\hline $\begin{array}{l}\text { Non-Salary } \\
\text { Incentives (NSI) }\end{array}$ & $\begin{array}{l}\text { Frequency of use and benefits to } \\
\text { institution in terms of retaining and } \\
\text { motivating researchers, for a range of } \\
\text { non-salary incentives. }\end{array}$ \\
\hline $\begin{array}{l}\text { Salary } \\
\text { Incentives (SI) }\end{array}$ & $\begin{array}{l}\text { Level of research staff remuneration } \\
\text { relative to similarly qualified } \\
\text { professionals in other research jobs in } \\
\text { the same country. }\end{array}$ \\
\hline $\begin{array}{l}\text { Internal } \\
\text { Interactions (II) }\end{array}$ & $\begin{array}{l}\text { The extent to which staff at all levels } \\
\text { are informed of, and involved in, key } \\
\text { research planning and review } \\
\text { procedures. }\end{array}$ \\
\hline $\begin{array}{l}\text { Research } \\
\text { Management (RM) }\end{array}$ & $\begin{array}{l}\text { Scoring checklist recording the } \\
\text { presence or absence of simple } \\
\text { documentation relating to the basic } \\
\text { functions of management; planning, } \\
\text { implementing, monitoring and } \\
\text { controlling research activity. }\end{array}$ \\
\hline
\end{tabular}

\subsection{Countries and institutions included in the survey}

The study aimed to survey forestry-related research capacity in the following countries of West and Central Africa: Benin, Cameroon, Côte d'Ivoire, Equatorial
Guinea, Gabon, Ghana, Nigeria, Republique Centralafricaine, Republique du Congo and Republique Democratique du Congo (formerly Zaire) (Table 3).

Some of the countries that were initially targeted for the study were later excluded, Republique Democratique du Congo and Republique du Congo were omitted because of the prevailing unfavourable political $/$ military/security situation during the study period. Equatorial Guinea does not have a forestry research institution in the country. Similarly, in the Republique Centralafricaine, no forestry research institute is operational although a national research institute is due to be established in 1999.

The institutional arrangements relating to the organisation of forestry-related research vary considerably by country. In some countries, this research is undertaken by only a few institutions, whilst in others it is disaggregated among a variety of establishments with differing mandates and capacities. The final coverage of institutions included in the survey sample is documented below.

\subsection{Limitations of study methodology}

There are a number of limitations associated with the study in general, and more specifically with the methodology adopted. An appreciation of these is important in evaluating the results. They include:

- an incomplete coverage of institutions involved in forestry-related research. The survey gave emphasis to the major players in individual countries;

- limitations associated with the individual indicators in capturing research capacity aspects. For example, using the ratio of support staff to research staff in gauging the extent of research support without first establishing the optimum ratio for the institution precludes conclusive results;

- survey data may be biased by the respondents providing information on behalf of an institution, or incomplete in which case a distorted description of the institutions' capacity for research could emerge. In many cases it is difficult to substantiate the information given by respondents; and

- there are various economic and social factors influencing the performance of the institutions surveyed for which indicators were not assigned, but for which a qualitative assessment was given. These included level of economic development of individual countries, endowment with forest resources, role of forestry in socioeconomic development of individual countries and forestry development in the public and private sectors.

These limitations notwithstanding, the methodology chosen is simple to understand yet provides useful information. Although the approach does not lend itself 
Table 3. Institutions surveyed, and others known to be involved in forestry-related research in West and Central Africa. BENIN

Unite de Recherché Forestière, Institut National de Recherché Agronomique du Benin.
Not Surveyed
Comments

Département d'Aménagment et de Gestion de

Lecturers/researchers of the Department of Forestry were not l'Environement, Faculté des Sciences Agronomiques (FSA), available at the time of data collection. There are estimated to be Université Nationale du Benin.

3 or $4 \mathrm{PhD}$ holders.

\section{CAMEROON}

- Secteur Environmental et Foret, Institut National de Recherché pour Developpment (INRA).

- Department of Forestry, Faculty of Agronomy and Agricultural Sciences, University of Dschang.

Not Surveyed

- Faculty of sciences, University Dschang.

- Faculty of sciences, University of Yaounde.

\section{COTE D'IVOIRE}

Département des Fôrets de l'Institut des Fôrets (IDEFOR/DFO).

Not Surveyed

Département de Forestiere de l'Ecole Nationale Superieure Agronomique de Yamoussokro.

GABON

Institut de Recherché en Ecologie Tropicale (IRET).

Not Surveyed

- Institut de Recherché Agronomique et Fore stiere (IRAF).

- Institut de Recherché en Technologie (IRT) Agricole et Forestière.

\section{GHANA}

- Forestry Research Institute of Ghana (FORIG).

- Department of Silviculture and Forest Management, Institute of Renewable Natural Resources, Unive rsity of Science and Technology.

Not Surveyed

Department of Wood Technology and Department of Agroforestry, Institute of Renewable Natural Resources, The agroforestry department has three lecturers/ researchers, the number in wood technology is unknown. University of Science and Technology.

\section{NIGERIA}

- Forestry Research Institute of Nigeria (FRIN).

- Department of Forest Resources Management, Faculty of Agriculture, University of Ibadan.

Not Surveyed

- Department of Wood Technology and Department of Wildlife and Fisheries, University of Ibadan.

- Departments of Forestry within Faculties of Agriculture

in other Nigerian Universities.
Comments

Some lecturers are involved in forestry-related research, but no co-ordinated forest-related research programme exists.

\section{Comments}

Omitted due to problems of access and communication.

Research capacity is unknown.

\section{Comments}

In IRAF and IRT there is an estimated combined total of 4 researchers specialised in forestry. to determination of optimum or absolute values of capacity for each institution, it has the merit of determining relative research capacity, i.e., how the capacity in one institution relates to another in the survey sample. It is also capable of highlighting some aspects of institutional comparative advantage, which are useful for the development of collaborative research among institutions. The approach is relatively efficient in summarising a large body of information relevant to a particular institution.

\section{Results and Discussion}

A discussion of the results is presented at two levels. First a brief overview is provided of research resources, namely research staff, financial resources, and research support facilities. The second part of the chapter is devoted to processes that enhance research capacity. These are examined in relation to how the institutions are able to manage and/or benefit from their external and internal environments. 


\subsection{Resources}

\subsubsection{Human resources}

Research is successfully conducted through the synergistic interplay of different skills. Senior scientists usually initiate research activities and solicit for their funding, some also manage the research process. Junior scientists largely execute the research work jointly with their seniors. Technicians provide invaluable inputs especially in the field and laboratories. Other supporting staff handle the research supporting functions like administration of human and physical resources. To optimise efficiency a range of different roles and skills are required. In this study the distribution of human resources according to these categories is examined in all institutions surveyed. However, the efficiency with which resources are deployed could not be assessed.

\section{Research scientists}

The distribution of human resources for research varies across the study area (Table 4). The public forestry research institutions in the Anglophone countries of Nigeria and Ghana have almost twice the number of scientific staff found in the five Francophone countries. The indicators for human resources (as shown in Annexes 1 and 4, and calculated as described in Annex 2) confirm this, with values of 391 and 327 for FRIN and FORIG respectively, compared with 138 and 123 for IRAD and IDEFOR, for example. Most of the researchers in Anglophone countries (about $89 \%$ ) have a research qualification M.Sc. and/or Ph.D.), while in the Francophone countries, with the exception of Cameroon, about $50 \%$ of the researchers have only a first degree. Expatriate research staff are uncommon and are only found in Cameroon and Côte d'Ivoire. There are very few female researchers, with the exception of Benin and Ghana. Women make less than $10 \%$ of the total research cadre; in fact for all countries they constitute only $10 \%$ the scientific research workforce.
The evolution of research and its relative importance in the Anglophone and Francophone countries may be related to the type of forest endowment in individual countries, the forestry objectives of the former colonial powers, and post-independence policies with respect to forestry development in the individual countries. It would appear that nations with significant closed rainforests adapted for logging and with small human populations per unit area have fewer forestry researchers compared to those with significant open forest formations where human populations per unit area are higher. The latter also tend to have greater areas of forest plantations.

Most of the experienced scientific staff is found in traditional forestry research institutions (Figure. 1). In the survey of SADC countries such expertise was largely found in universities (Kowero and Spilsbury 1997).

Figure 1. Distribution of scientific staff by institute.

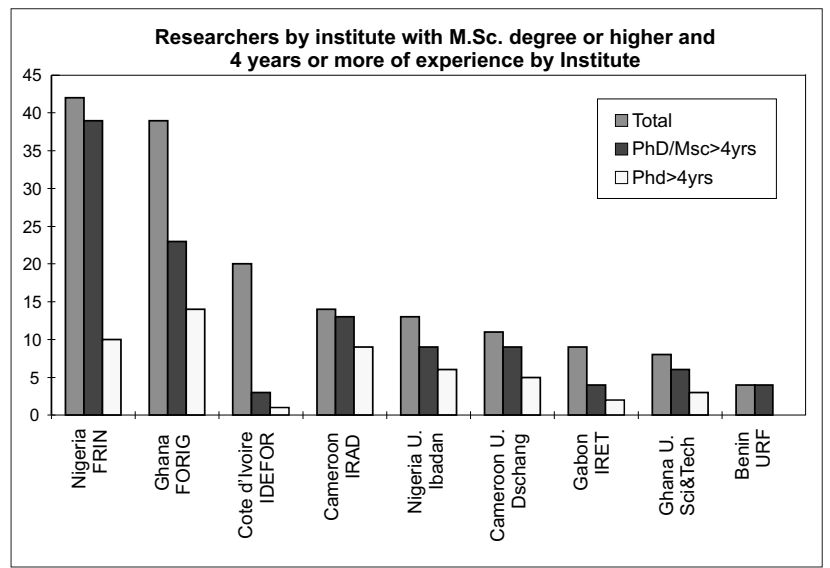

In terms of numbers, Nigeria appears to have more qualified and experienced researchers, i.e. those with M.Sc. and Ph.D. qualifications and over 4 years of experience. However, as a proportion of the total in each institution, Benin, Cameroon Nigeria and Ghana have more than 60\%

Table 4. Human resources from the survey sample aggregated by country.

\begin{tabular}{|c|c|c|c|c|c|c|c|c|c|}
\hline COUNTRY & Total & $\begin{array}{c}\% \text { of } \\
\text { sample total }\end{array}$ & $\begin{array}{c}\% \\
\text { female }\end{array}$ & Ph.D. & M.Sc. & B.Sc. & Expat. & $\begin{array}{l}\text { Ph.D. or M.Sc. } \\
\&>10 \text { years }\end{array}$ & $\begin{array}{l}\text { Ph.D. or M.Sc. } \\
\&>4 \text { years }\end{array}$ \\
\hline NIGERIA & 55 & 34.4 & 7.3 & 18 & 36 & 1 & 0 & $\begin{array}{c}40 \\
(72.7 \%)\end{array}$ & $\begin{array}{c}48 \\
(87 \%)\end{array}$ \\
\hline GHANA & 47 & 29.4 & 19.2 & 20 & 17 & 10 & 0 & $\begin{array}{c}14 \\
(29.8 \%)\end{array}$ & $\begin{array}{c}29 \\
(61 \%)\end{array}$ \\
\hline CAMEROON & 25 & 15.6 & 4.0 & 14 & 9 & 0 & 2 & $\begin{array}{c}18 \\
(72 \%)\end{array}$ & $\begin{array}{c}22 \\
(88 \%)\end{array}$ \\
\hline CÔTE D'IVOIRE & 20 & 12.5 & 5.0 & 2 & 5 & 11 & 2 & 0 & $\begin{array}{c}3 \\
(15 \%)\end{array}$ \\
\hline GABON & 9 & 5.6 & 0 & 2 & 2 & 5 & 0 & $\begin{array}{c}4 \\
(44.4 \%)\end{array}$ & $\begin{array}{c}4 \\
(44.4 \%)\end{array}$ \\
\hline BENIN & 4 & 2.5 & 25.0 & 0 & 4 & 0 & 0 & $\begin{array}{c}4 \\
(100 \%)\end{array}$ & $\begin{array}{c}4 \\
(100 \%)\end{array}$ \\
\hline CAR & 0 & 0.00 & 0 & 0 & 0 & 0 & 0 & & 0 \\
\hline TOTALS & 160 & 100 & 10.0 & 64 & 69 & 27 & 3 & $\begin{array}{c}80 \\
(50 \%)\end{array}$ & $\begin{array}{c}110 \\
(68.8 \%)\end{array}$ \\
\hline
\end{tabular}


of their researchers in this category. One hypothesis is that people with this level of qualification and experience are best equipped to conduct research. They have the capacity to formulate, direct, interpret and synthesise research results. They could occupy leadership positions within their institutions, positions that can influence the direction of research. In short this group would most probably constitute the major human driving force in research.

About $73 \%$ of researchers in Nigeria hold an M.Sc. and/ or Ph.D., and more than ten years experience. This raises questions regarding the age 'cohorts' of scientific staff and further studies may establish whether sufficient 'young blood' is being recruited into the research system. Cameroon and Benin are in the same situation with $72 \%$ and $100 \%$, respectively, of their research manpower in this category. However, the situation is very different in Ghana, which ranks second in number of experienced researchers available, but only about $30 \%$ of its researchers hold M.Sc. and/or Ph.D. degrees with more than ten years experience. It has a sizeable pool of M.Sc. and B.Sc. holders in its research institutions who can be trained to replace those who retire or leave for other reasons.

Over the period 1993-1996 the number of research staff at IDEFOR declined from 22 to 19, and at FRIN from 59 to 50 scientists. For FORIG, during the same period, total staff has increased from 37 to 42 . For the other institutions staff numbers have remained relatively constant.

Overall, the region appears to have an imbalance between well-trained and experienced scientific staff, on one hand, and less experienced research scientists on the other. The situation may be aggravated in the future, as experienced scientists retire and those remaining assume more administrative functions. Many of these countries are implementing economic reform measures that have made, and will continue to make, it difficult to expand their human resources with younger staff. A cursory inspection of the data reveals that there is a similar imbalance between the numbers of female and male researchers (Figure 2).

Figure 2. Gender balance of research staff by institute.

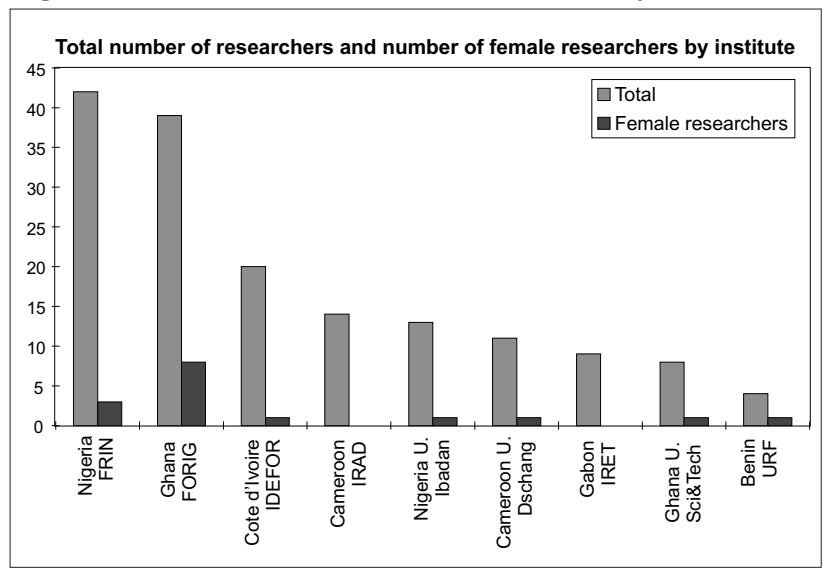

\section{Administrative and technical support staff}

Administrative/secretarial and technical staff support research activities. This survey compares the distribution of the first two types and also considers gender account (Table 5a). Hired labour also plays a role in supporting research but this aspect was not considered in detail.

Table 5a. Distribution of supporting staff by institution.

\begin{tabular}{|c|c|c|c|c|c|c|c|c|c|}
\hline \multirow[t]{2}{*}{ INSTITUTION } & \multicolumn{4}{|c|}{ Administrative } & \multicolumn{4}{|c|}{ Technical } & \multirow{2}{*}{$\begin{array}{l}\text { Technical Suppor } \\
\text { Indicator }^{\text {b }}\end{array}$} \\
\hline & Male & $\begin{array}{c}\text { Female } \\
(\%)\end{array}$ & Total & Ratio $^{a}$ & Male & $\begin{array}{c}\text { Female } \\
(\%)\end{array}$ & Total & Ratio $^{a}$ & \\
\hline FRIN & 156 & $\begin{array}{c}78 \\
(33.3)\end{array}$ & 234 & 5.5 & 187 & $\begin{array}{c}8 \\
(4.1)\end{array}$ & 195 & 4.6 & 10.1 \\
\hline Univ. IBADAN & 4 & $\begin{array}{c}3 \\
(42.9)\end{array}$ & 7 & 0.5 & 3 & $\begin{array}{c}2 \\
(40)\end{array}$ & 5 & 0.4 & 0.9 \\
\hline FORIG & 44 & $\begin{array}{c}13 \\
(22.8)\end{array}$ & 57 & 1.5 & 49 & $\begin{array}{c}10 \\
(16.9)\end{array}$ & 59 & 1.5 & 3.0 \\
\hline IRNR & 0 & $\begin{array}{c}1 \\
(100)\end{array}$ & 1 & 0.1 & 2 & $\begin{array}{c}0 \\
(0)\end{array}$ & 2 & 0.3 & 0.4 \\
\hline Univ. Dschang & 0 & $\begin{array}{c}2 \\
(100)\end{array}$ & 2 & 0.2 & 4 & $\begin{array}{c}0 \\
(0)\end{array}$ & 4 & 0.4 & 0.6 \\
\hline IRAD & 8 & $\begin{array}{c}7 \\
(46.7)\end{array}$ & 15 & 1.1 & 9 & $\begin{array}{c}6 \\
(40)\end{array}$ & 15 & 1.1 & 2.2 \\
\hline IDEFOR & 5 & $\begin{array}{c}5 \\
(50)\end{array}$ & 10 & 0.5 & 37 & $\begin{array}{c}0 \\
(0)\end{array}$ & 37 & 1.9 & 2.4 \\
\hline IRET & 0 & $\begin{array}{c}1 \\
(100)\end{array}$ & 1 & 0.1 & 3 & $\begin{array}{c}0 \\
(0)\end{array}$ & 3 & 0.3 & 0.4 \\
\hline URF & 1 & $\begin{array}{c}1 \\
(50)\end{array}$ & 2 & 0.5 & 4 & $\begin{array}{c}0 \\
(0)\end{array}$ & 4 & 1 & 1.5 \\
\hline
\end{tabular}


The ratio of number of technicians and administrative staff to number of researchers within an institution was used to gauge the level of technical and administrative support available. No attempt was made to determine the 'ideal' ratio as this will vary by institute and research focus. In universities it was recognised that students provide technical support to research, but this varies considerably and is a factor that was not considered in this ratio.

Nigeria and Ghana have the largest numbers of research support staff. FRIN of Nigeria has about five administrative and five technical staff to every scientist, and this is by far the highest proportion in all countries. It also has the highest percentage of senior scientific staff who may have both administrative and research functions. FRIN has 11 outstations/colleges, which may partly explain the high levels of support staff (Table 5b).

Table 5b. Research support indicator values.

\begin{tabular}{lc}
\hline INSTITUTION & $\begin{array}{c}\text { Support Staff } \\
\text { per Researcher }\end{array}$ \\
\hline URF & 1.5 \\
IRAD & 2.2 \\
U.DSCHANG & 0.6 \\
IDEFOR & 2.4 \\
IRET & 0.4 \\
FORIG & 3.0 \\
IRNR & 0.4 \\
FRIN & 10.1 \\
U.IBADAN & 0.9 \\
\hline
\end{tabular}

Bengston et al. (1988) observed that technical support for research in developing countries in the Asia-Pacific was higher in government research institutions. This also seems to be true for West and Central Africa in the late 1990s. FRIN has a more than ten support staff per researcher. This seems to be a very high ratio, however, FRIN's research activities are dispersed among its many research stations that cover the range of ecological regions in the country, presumably increasing the numbers of support staff required. FORIG, IDEFOR and IRAD have more than two support staff per scientist but the universities have lower ratios of support staff per researcher. As already noted, students often provide such support in universities.

Nigeria and Ghana also have the most female employees, although they constitute less than $45 \%$ of total support staff. Some of the other countries have higher proportions but the numbers involved are very small.

In comparison to the survey of SADC countries (Kowero and Spilsbury 1997), about half of the institutions surveyed had less than one technician for every researcher. However, the figures should be interpreted with caution as research institutions tend to have their own technicians, laboratories and equipment, while university departments and faculties are more inclined to share some of these resources because of central management.

\subsubsection{Financial resources}

The availability of funds is a prerequisite for the establishment and maintenance of organisations that undertake research. The importance of a long-term, stable supply of funds to the development and maintenance of research capacity is an issue which has been strongly emphasised in the literature (Burley et al. 1989; African Academy of Sciences 1994; Someshwar 1994; Walton 1994; World Bank 1996a; Szaro et al. 1998), and by the staff of the research institutes in Africa themselves.

In the conduct of the research capacity survey, financial data were classified into two broad categories: local and foreign research funds. The former includes all research funds originating within an institute's own country, whilst the latter includes contributions to the research budget that originate outside an institute's country. The figures represent the net budget available after staff salaries and allowances have been deducted.

Unfortunately, few institutions were able to provide comprehensive information with respect to their financial resources. Not all institutions provided data on their research operational costs (excluding salaries of employees, see Table 6).

Table 6. Percentage of total reported budget allocated to salaries.

\begin{tabular}{lcccc}
\hline INSTITUTION & 1996 & 1995 & 1994 & 1993 \\
\hline IRNR & 79 & 87 & 88 & 88 \\
IRET & 23 & 20 & 22 & 24 \\
U. Dschang & 67 & 60 & 58 & 69 \\
FORIG & 59 & 46 & 50 & 54 \\
IDEFOR & 50 & 59 & 43 & 38 \\
FRIN & 74 & 83 & 85 & 84 \\
\hline
\end{tabular}

In general, and in conformity with the findings of the SADC study, the extent of funding for many governmentfinanced institutions is frequently inadequate, often shows considerable annual variation, and in many cases bears no relation to the volume of work on the stated research agenda. Of course the adequacy of any budget is highly dependent on the type of research work undertaken. In the majority of institutions, local funds originate directly from government sources and are usually sufficient only to cover staff salaries and running costs. The specific case of IDEFOR in Côte d'Ivoire, provides a contrast however, all research funds originate from local sources through contractual financial arrangements with the National Forestry Development Corporation.

One generaliseable observation is that the actual research undertaken by institutions in the region is frequently a 
function of donor's funding preferences. This raises the question of how well funded research conforms to the national perception of the highest research priorities.

Financial resources are particularly vulnerable to political and economic externalities that generate uncertainty and create serious strains on the institutions, inhibiting their capacity to deliver or meet expectations. Externalities such as currency exchange fluctuations, for example, can greatly alter the 'buying power' of the research budget. If a currency is devalued, as was the case for Cameroon, Côte d'Ivoire, Gabon and Benin in 1994, and more recently with Nigeria, then the 'buying power' of the local currency research budget is diminished in relation to imported inputs. Value of funds from external ('hard currency') sources appreciates in the domestic market. During the period of analysis, many governments were still implementing economic austerity measures. Under such conditions institutions with a high proportion of foreign funding are better cushioned from adverse effects compared to those with heavy reliance on government funding. In real terms, government funding of agricultural research in the region is declining (Gakale et al. 1996). In these circumstances, access to external sources of funding is critical.

Another noteworthy trend in recent years that has influenced the financing of research has been a tendency for donors to prefer using NGOs rather than public sector institutions for the implementation of both research and development projects. It is common for development projects in natural resource sectors to also have a research component. However, these non-governmental implementing agencies often have very little permanent research capacity in terms of human resources. In this regard they behave like consultancy firms, hiring research expertise on a temporary contractual basis, as needed. The obvious source for such expertise is located in the public sector research institutes and universities, and often results in research institutions losing control of the activities of their researchers as each responds as an individual to the 'market' opportunities.

While utilisation of international sources of finance for research is commendable, institutions should also develop other financing mechanisms. These could include raising funds from industry and private sector through contracting of services, charging an overhead on the use of their researchers as consultants, and the feedback of a proportion of revenue from taxes on selling standing timber to public sector research institutions. However, in West and Central Africa there is generally insufficient demand for market-driven forestry research. Primary forest production is still very much under government control, either directly or through the award of logging concessions to the private sector contractors. The private sector tends to dominate the wood-processing industry but the level of investment in research and development is low and consequently represents a poor market for the services of many research institutions.

\subsubsection{Research support facilities}

A brief survey was made of research facilities available in these institutions including laboratories, libraries and computers. The condition of field stations/centres/ zones in some of the institutions was appraised. The level of sharing of some of these facilities was also examined (Table 7).

Table 7. Summary of research support facilities.

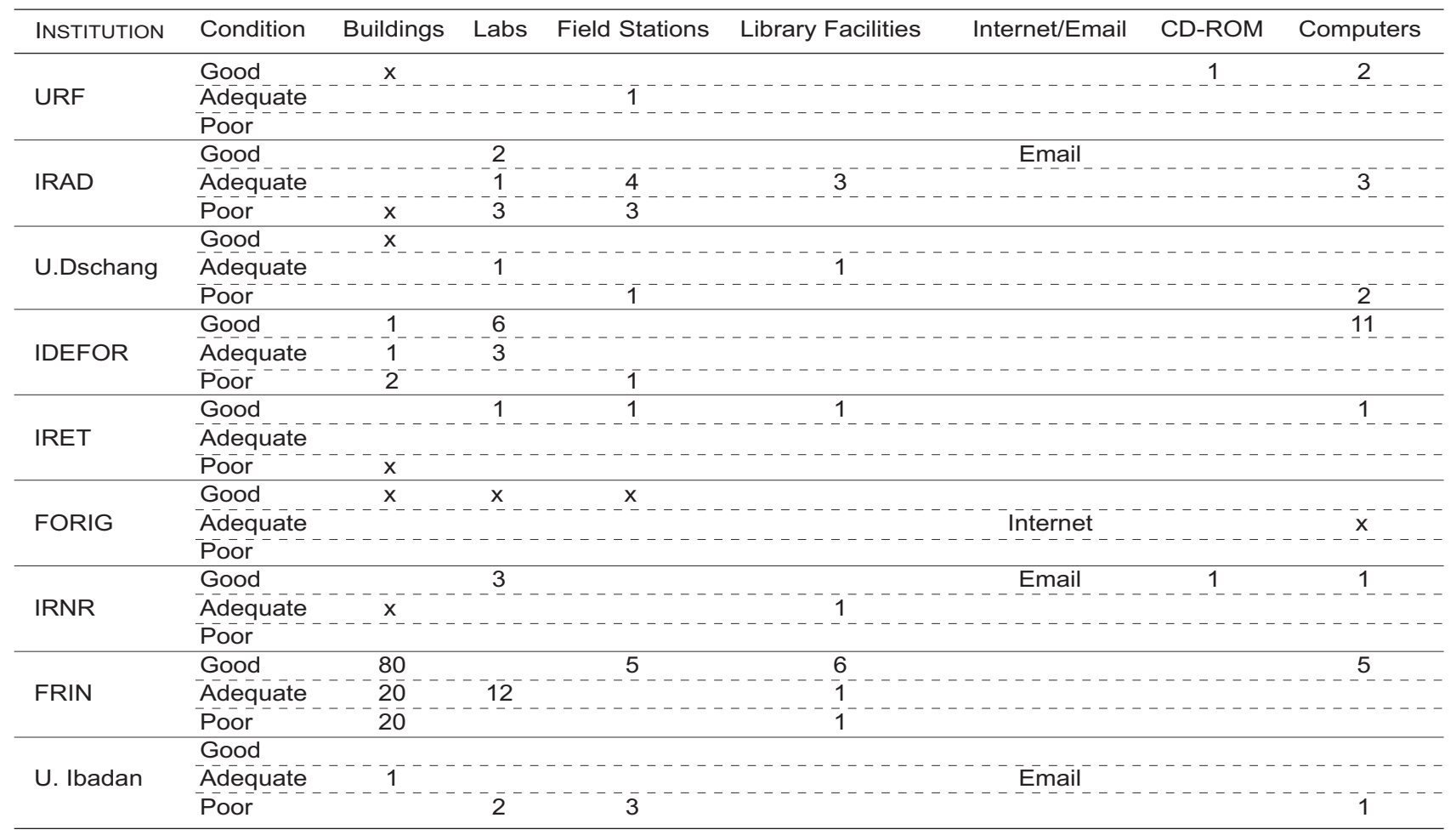




\subsection{Research environment}

The manner in which research institutions interact with their environment has an important impact on their capacity. New modes of donor support for research are increasingly favouring partnerships both between ARIs in donor nations and those in nascent research systems, and also between institutes in the same country or region. Organisations best able to respond to these developments are those that have already had experience in collaborative research activities. Such institutions will show a greater level of research interaction as captured by the various indicators used in the study.

This section presents results relating to interactions between institutions in individual countries, as well as how individual institutions relate to one another in the sample. Annex 3 presents results for individual institutions.

\subsubsection{External research environment}

Interactions between research institutions

Respondents reported the types of interaction and perceived benefits derived from these research-related interactions (Table 8). They include; sharing resources and facilities such as laboratories, collaborative research activities and concomitant manpower development/ training, exchange of publications and information, transfer of research results, participation in conferences and seminars and facilitation of acquisition of funding. forestry research establishments in their own countries. Of the institutions surveyed $66 \%$ reported that they derive moderate benefits from interacting with national forestry and related institutions with the remainder perceiving such interactions to be very beneficial. URF of Benin, IRNR of Ghana and FORIN of Nigeria reported frequent and beneficial contacts.

\section{(b) Interactions with national non-forestry research institutions}

These interactions may indicate the extent to which forestry research is accommodating or being accommodated outside mainstream forestry research institutions, i.e., opportunities for research to 'spill-over' into other research areas or for expertise outside the traditional forestry sector to 'spill-in' to their research activities and approaches.

Four of the nine institutions surveyed reported frequent interactions, another four reported occasional interactions and no interactions were reported for IRET in Gabon. However, only two institutes perceived such interactions to be very beneficial, IRAD in Cameroon and IRNR in Ghana, while only University of Dschang perceived there being no real benefits resulting from such relationships. The level of interaction between the institutions is indicative of the potential for and extent of collaborative forestry research work in each of these countries. The frequency of contact coupled with analysis of the types of research topics that are currently undertaken leads to

Table 8. Research interactions by institution and their perceived value.

\begin{tabular}{|c|c|c|c|c|c|c|c|c|}
\hline \multirow[t]{2}{*}{ INSTITUTION } & \multicolumn{2}{|c|}{ FRIs in own country } & \multicolumn{2}{|c|}{ Non-FRI own country } & \multicolumn{2}{|c|}{ FRIs in region } & \multicolumn{2}{|c|}{ FRIs outside region } \\
\hline & Freq. & Benefit & Freq. & Benefit & Freq. & Benefit & Freq. & Benefit \\
\hline URF & 2 & 3 & 2 & 2 & 1 & 2 & 2 & 3 \\
\hline IRAD & 2 & 2 & 2 & 3 & 1 & 3 & 2 & 2 \\
\hline U.Dschang & 2 & 2 & 1 & 1 & 0 & 0 & 1 & 1 \\
\hline IDEFOR & 2 & 2 & 2 & 2 & 2 & 3 & 2 & 3 \\
\hline IRET & 1 & 2 & 0 & 0 & 0 & 0 & 1 & 1 \\
\hline FORIG & 1 & 2 & 2 & 2 & 1 & 2 & 1 & 2 \\
\hline IRNR & 2 & 3 & 1 & 3 & 1 & 2 & 1 & 1 \\
\hline FRIN & 2 & 3 & 1 & 2 & 1 & 2 & 1 & 2 \\
\hline U.Ibadan & 2 & 2 & 1 & 2 & 1 & 2 & 1 & 2 \\
\hline
\end{tabular}

Notes: The categories of interaction surveyed were: forestry-related research institutions in own country; non-forestry related research institution in own country; forestry-related research institutions in the W. \& C. Africa region; and forestry research institutions outside the W. \& C. Africa region. Values for frequency: 0 = never; 1 = occasionally; 2 = frequently.

Values for benefit in assisting research: 1 = minimal benefit; 2 = moderate benefit; 3 = very beneficial.

\section{(a) Interactions with forestry-related national research} institutions

It appears that contacts between individual institutions surveyed and other national forestry-related institutions are frequent and moderately beneficial in practically all cases. The exceptions are FORIG in Ghana and IRET in Gabon which reported occasional interactions with the conclusion that most forestry research is still targeted at 'traditional' forestry research issues and approaches. There is considerable scope to enhance collaborative arrangements between the mainstream forestry research institutions and sources of research expertise from other disciplines that are present in other sectors in each of the countries. 
(c) Interactions with research institutions based in other countries in the region

The frequency of interaction between the research institutions and their local counterparts on one hand, and research organisations located in other countries in the region on the other, is markedly different. Approximately $89 \%$ of the institutions surveyed either have only occasional contact or none at all. However, where there are interactions ( $88 \%$ of the total sample) they are of moderate $(56 \%)$ or high $(22 \%)$ benefit. The survey also elicited qualitative information on which institutions were most commonly involved in these interactions. There were few commonalities across the survey sample with the exception of FORIG, which was mentioned by four institutions.

(d) Interactions with research institutions based outside the West and Central African region

All the surveyed institutions have interactions with research organisations outside of the West and Central African region, with 33\% reporting frequent links and the remainder having occasional contact. Moderate benefits were reported by $44 \%$ of the sample, and $22 \%$ reported interactions to be very beneficial. One-third feel that no real benefit accrued as a result of these collaborations. ICRAF, IITA, CIRAD Forêt and TROPENBOS were mentioned by several respondents. All of these institutions have regional research programmes and offices (IITA has its headquarters in Nigeria) in West and Central Africa, which together explains the frequency of their citation as collaborators. It is worthy of note that although CIFOR has been operational in West and Central Africa, it was not mentioned in connection to research interactions. This implies that CIFOR may be dealing with individual scientists in their own capacity and as consultants, and not with their institutions per se. Alternatively CIFOR research activity does not link well into national forestry research programmes that focus on the traditional forestry research agenda. This may explain what appears to be a limited area of research convergence between CIFOR and national institutions. This obviously limits the possible effectiveness of any CIFOR capacity building impact on traditional forestry research institutions, and may also have implications for the eventual impact of CIFOR's findings.

\section{(e) Relative standing with respect to each of the research interactions}

The analysis was extended to consider how interactions reported by individual institutions (as discussed above) relate to the sample as a whole. For each institution the value for research interaction was calculated as detailed in Annex 2, and its relative standing in the data set identified (Annex 1). This enabled the data for each institute to be expressed in relation to the sample as a whole, in addition to the construction of charts for each (Annex 3). The charts give an impression of how each institution relates to similar institutions in the region with respect to the chosen indicators.

From this second level of analysis, it would appear that in contrast to the findings in the previous SADC survey, the national forestry research institutes in West and Central Africa rather than the universities, have a greater frequency of and derive greater benefit from research interactions. FRIN, FORIG and IDEFOR are the highest in the rankings. This is partly linked to the size of the national institutions in terms of staff numbers relative to the others, i.e., because they have a larger staff cadre they also have a higher absolute level of interaction. However, even for an indicator unweighted by staff numbers, the national forestry research institutes of IDEFOR, URF Benin and IRAD Cameroon, have the highest combined level of frequency and benefit from research interactions (Table 8).

\section{Interactions with educational institutions}

Evaluation of interactions with educational institutes was again made at two levels: the level of individual institutions and that relative to others in the sample (Table 9). The types of interaction and benefits included in this aspect are: supervision and mentoring of research students; exchange of library and computer based resources, e.g., databases; training of personnel; and exposure to new research ideas, methods and findings.

Table 9. Educational interactions and their perceived value.

\begin{tabular}{|c|c|c|c|c|c|c|}
\hline \multirow[t]{2}{*}{ INSTITUTION } & \multicolumn{2}{|c|}{$\begin{array}{l}\text { Ed. institutes in } \\
\text { own country }\end{array}$} & \multicolumn{2}{|c|}{$\begin{array}{l}\text { Ed. institutes } \\
\text { in region }\end{array}$} & \multicolumn{2}{|c|}{$\begin{array}{l}\text { Ed. institutes } \\
\text { outside region }\end{array}$} \\
\hline & Freq. & Benefit & Freq. & Benefit & Freq. & Benefit \\
\hline URF & 1 & 2 & 0 & 0 & 0 & 0 \\
\hline IRAD & 2 & 2 & 1 & 2 & 2 & 2 \\
\hline U.Dschang & 1 & 2 & 0 & 0 & 1 & 2 \\
\hline IDEFOR & 2 & 1 & 0 & 0 & 2 & 2 \\
\hline IRET & 2 & 2 & 0 & 0 & 2 & 2 \\
\hline FORIG & 2 & 2 & 0 & 0 & 2 & 2 \\
\hline IRNR & 1 & 2 & 0 & 0 & 2 & 3 \\
\hline FRIN & 2 & 3 & 1 & 2 & 0 & 0 \\
\hline U.Ibadan & 2 & 2 & 0 & 0 & 1 & 2 \\
\hline
\end{tabular}

Notes: The categories of interaction surveyed are: educational institutions in own country; educational institutions in another countries in the W. \& C. Africa region; and educational institutions outside the W. \& C. Africa region.

Values for frequency: $0=$ never, 1 = occasionally, 2 = frequently.

Values for benefit in assisting research: $1=$ minimal benefit; $2=$ moderate benefit; $3=$ very beneficial.

\section{(a) Interactions with national educational institutions}

All institutions surveyed reported interactions with educational institutions in their own country, with $66 \%$ reporting that these interactions were frequent. Most 
interactions in this category (77\%) were perceived to be of moderate benefit but only FRIN of Nigeria regarded these interactions as very beneficial. Generally, the majority of research institutions consider contacts with educational establishments in their own countries as being moderately beneficial either because staff has been trained in these institutions or because they share some research facilities.

\section{(b) Interactions with research institutions based in other countries in the region}

One of the striking features emerging from the survey is the general absence of interactions with educational institutions in other countries within the West and Central African region. Possible reasons for this include: language limitations between Anglophone and Francophone institutions; training institutions for research manpower available within countries, especially for Nigeria, Ghana and to a lesser extent Cameroon; and source/nature/conditions of scholarships for training may impose restrictions on location of training.

\section{(c) Interactions with research institutions based outside the West and Central African region}

Interactions with educational institutions in countries outside the region were reported by seven institutions $(77 \%)$ with six of these $(66 \%)$ perceiving moderate benefits and one institution perceiving the interactions to be very beneficial. The contacts were with a variety of organisations and no patterns were observed in the survey responses, except to note that they were with institutions of high research capacity in Europe or North America. Again, this is similar to the situation observed in the SADC survey where interactions with foreign institutions, particularly those from countries outside of the region, were viewed as the most beneficial. Most of the contacts with foreign educational centres outside the region are related to post-graduate training of researchers and their frequency is most likely related to the limited training possibilities available elsewhere in the region, this would account for the low level of interaction noted in the preceding section.

(d) Relative standing with respect to interactions with educational institutions

In the second level of the analysis, the level of interaction with educational institutions is examined for each institution relative to others in the region. The procedure for determining the value of educational interactions is explained in Annex 2. As in the analysis of research interactions the same approach was followed in ranking the institutions and in constructing charts for each (Annex 3).

This presents a similar the pattern to that described earlier with respect to research interactions. The national forestry research institutions of Ghana, Nigeria and Cameroon (FORIG, FORIN and IRAD respectively) have the highest indicator levels while the University of Dschang, IRNR and University of Ibadan tend to have a lower level of contact with educational institutes.

\section{Interactions with users of research results}

The interactions of these institutions with users of their research results will influence the ultimate effectiveness of research. Two proxies have been used to gauge this interaction (Table 10). This is the proportion of annual budget associated with technical transfer and extension and the proportion of staff time associated with technical transfer of results to user groups.

Table 10. Budget and staff time allocated to interactions with research user groups.

\begin{tabular}{|c|c|c|c|}
\hline \multirow[t]{2}{*}{ INSTITUTION } & Budget & Staff Time & \multirow[t]{2}{*}{ Indicator } \\
\hline & \multicolumn{2}{|c|}{$\%$} & \\
\hline URF & 0 & 5 & 1.1 \\
\hline IRAD & 15 & 25 & 34.7 \\
\hline U.DSCHANG & 10 & 5 & 13.1 \\
\hline IDEFOR & $0^{b}$ & 50 & 56.3 \\
\hline IRET & 0 & 5 & 2.5 \\
\hline FORIG & 5 & 10 & 26.9 \\
\hline IRNR & 2 & 10 & 6.5 \\
\hline FRIN & 10 & 20 & 57.3 \\
\hline U.IBADAN & & & 8.7 \\
\hline
\end{tabular}

$\mathrm{a}=$ Indicator value calculated as detailed in Annex 2;

$\mathrm{b}=$ Budget comes from external project funds, not institutional budget.

\section{(a) Level of commitment of resources to user groups}

As a general pattern, research institutes allocate a very small percentage of their budgets to interactions with, or transfer of information to, user groups. The type of user group varies both within and between institutions, most commonly reference is made to development projects, NGOs, extension services, local communities and private companies. Typically, less than $10 \%$ of the budget is allocated to interactions with these groups. This is either because there is little emphasis on the transfer of research results to promote their eventual adoption or because resources for these purposes are considered as part of the research budget at the research project level. Staff time allocated to interactions with user groups was also generally less than $10 \%$ with the exception of IDEFOR, which allocated approximately half of its available staff time to interactions with users. FRIN was also notable as its institutional structure provided for specialist scientists to promote the transfer of research to user groups, presumably through coordinated activities at FRIN's various field stations across the country.

(b) Standing of individual institutions relative to others Each of these institutions was evaluated relative to the 
others in the sample as explained in Annex 2, leading to the charts presented in Annex 3. The general pattern shows that the main national public sector research institutes dominate the rankings of the user interactions indicator; FRIN, IDEFOR, IRAD and FORIG attaining indicator values that are far higher than the rest of the sample. IRET in Gabon and URF in Benin seem to have very little linkages with research users, which beings into question the eventual usefulness of the research outputs.

\subsubsection{Internal research environment}

\section{Internal research interactions}

This aspect of the study attempted to elicit information that reflects the level of involvement of different categories of staff and user groups in formal meetings and procedures relating to research management or the exchange of scientific information within a research institution. The underlying hypothesis is that wellmanaged research institutes are often characterised by staff at all levels who are well informed of, and involved in, key research planning and review procedures. Collective 'ownership' of strategies and priorities is an important component of an institutional 'research culture'. An effective research institute will actively promote the transfer of research information between different categories of staff, leading to improved understanding of mandate and a common sense of purpose. For a detailed description see Annex 2. It also attempts to capture both the frequency and benefit derived from contact (Table 11).
Project selection meetings at the institute level seem to happen less often than other types of meeting. Progress monitoring is generally more frequent than planning activities and is associated with a greater level of benefit for promoting research. Information acquisition through staff seminars occurs frequently and is associated with a perception that its influence on the research process is of great value.

Reference to the indicator values for internal interactions in Annex 1 shows that FORIG and FRIN lead the ranking for this aspect, while IDEFOR and IRET are least active. Anglophone institutions appear to adopt a more participatory approach to key research management processes than do the Francophone countries. However, the small sample size and the qualitative nature of the data do not allow for this conclusion to be drawn with a high level of certainty.

\section{Salary and related incentives}

All the institutions in the survey sample receive funds to meet the base salary costs of their researchers from the public purse. However, scientists from many of the institutions surveyed find it difficult to depend solely on their salaries for survival. This is mainly due to the difficult economic climate prevailing in practically all these countries. A similar pattern was observed in the earlier study of the SADC region.

In response, many research institutions have developed supplementary measures in collaboration with their

Table 11. Internal interactions - indicator values, meeting types, frequency of meetings and perceived benefits.

\begin{tabular}{|c|c|c|c|c|c|c|c|c|c|c|c|}
\hline \multirow[t]{3}{*}{ INSTITUTION } & \multirow{3}{*}{$\begin{array}{l}\text { Indicator } \\
\text { Values }\end{array}$} & \multicolumn{4}{|c|}{ Research 'portfolio' level } & \multicolumn{4}{|c|}{ Project level } & \multirow{2}{*}{\multicolumn{2}{|c|}{$\begin{array}{l}\text { Seminars, } \\
\text { staff \& visiting } \\
\text { scientists }\end{array}$}} \\
\hline & & \multicolumn{2}{|c|}{$\begin{array}{l}\text { Project Selection } \\
\text { meeting }\end{array}$} & \multicolumn{2}{|c|}{$\begin{array}{c}\text { Research progress } \\
\text { meeting }\end{array}$} & \multicolumn{2}{|c|}{$\begin{array}{l}\text { Project planning } \\
\text { meeting }\end{array}$} & \multicolumn{2}{|c|}{$\begin{array}{l}\text { Research progress } \\
\text { meeting }\end{array}$} & & \\
\hline & & Freq. & Benefit & Freq. & Benefit & Freq. & Benefit & Freq. & Benefit & Freq. & Benefit \\
\hline URF & 43 & 1 & 3 & 3 & 3 & 2 & 3 & 3 & 3 & 1 & 2 \\
\hline IRAD & 47 & 0 & 0 & 0 & 0 & 1 & 3 & 3 & 3 & 3 & 3 \\
\hline DSCHANG & 41 & 1 & 2 & 2 & 3 & 1 & 3 & 2 & 3 & 3 & 3 \\
\hline IDEFOR & 31 & 0 & 0 & 2 & 3 & 1 & 3 & 2 & 3 & 2 & 2 \\
\hline IRET & 31 & 1 & 2 & 0 & 0 & 1 & 2 & 1 & 2 & 1 & 3 \\
\hline FORIG & 57 & 1 & 3 & 2 & 3 & 1 & 3 & 2 & 2 & 3 & 3 \\
\hline IRNR & 49 & 2 & 2 & 2 & 3 & 2 & 2 & 2 & 2 & 4 & 3 \\
\hline FRIN & 63 & 1 & 3 & 1 & 3 & 3 & 3 & 3 & 3 & 3 & 3 \\
\hline \multirow[t]{2}{*}{ U.IBADAN } & 48 & 0 & 2 & 1 & 2 & 1 & 2 & 1 & 2 & 4 & 3 \\
\hline & TOTALS & 7 & 17 & 13 & 20 & 13 & 24 & 19 & 23 & 24 & 25 \\
\hline
\end{tabular}

Notes: The indicator includes weighting for the types of staff involved in the meeting.

The frequency of the meeting or formal procedure has the following values: $0=$ never; $1=$ once a year; $2=$ every six months; $3=$ every month; 4 = every week.

The level of benefit (contributing to research) has the following values: $0=$ no real benefit; $1=$ low level of benefit; $2=$ moderate benefit; $3=$ high level of benefit. 
national governments to lessen these economic hardships on employees. Such measures include additional allowances and payments for researchers over and above those that are payable to mainstream civil servants and relate to research-specific activities. The type and amount of these additional funds vary from country to country. Such allowances and payments are generally not regarded as a component of salary for two reasons; firstly to provide a rationale for not extending these incentives to the wider civil service cadre and secondly, to avoid additional costs on pension payments that are usually linked to base salary. For example, in the case of Cameroon these allowances and payments may represent as much as a $30 \%$ increase on base salary of Dschang and IRAD employees over and above mainstream non-research civil servants. These incentives were introduced by Presidential Decree during the 1960 s to avoid a 'brain drain'. In Gabon, the magnitude of these allowances is five times that of similar allowances in Cameroon.

Despite the provision of these additional financial incentives it is not unusual to find that individual researchers have difficulty surviving on their salaried income. IN response, they develop their own 'livelihood strategies', most often manifested through their availability for, and enthusiasm to undertake, private consultancy assignments. Although this is of obvious benefit for the individual it implies a cost to the institutes, in terms of staff time foregone and a reduction in the control that managerial staff have over the work programme of their researchers. This tendency was most notable in Nigeria and Ghana where the salary differentials between the public sector and other employers were greatest (Table 12).
In all the institutions surveyed, salaries are still the major source of income for the majority of researchers. However, when the level of salary income is compared to professionals of similar qualifications employed either in other public sector organisations, the private sector or in NGOs, the level of remuneration for public sector researchers is markedly lower. The magnitude of this 'income gap' between public sector employees and the private sector/NGOs shows a high level of variability. For example, employees in international NGOs can sometimes earn as much as six times the salary of a public sector research employee.

These data must be interpreted carefully. Respondents were asked to make comparisons between similarly qualified professionals in different categories of institutions within the same national economy. This provides some insight into the competitiveness of the research institute in the local employment market. There are difficulties in making direct comparisons, in hard currency terms, across countries. The differences may be as much to do with economic externalities such as currency devaluation (as in the case of Nigeria) as they are to do with the institutional willingness, or ability, to pay competitive salaries.

The fact that IDEFOR and IRET appear in the first quartile for the salary incentive indicator may not mean that the staff of these institutions has the highest level of remuneration in comparison with the others in the sample. In this respect, the indicator values presented in Annex 1 do not provide a comparison of relative values of remuneration; rather they show how the remuneration of researchers in one country compare with those of scientists of equivalent qualifications employed in other institutions in the same country.

Table 12. Salary incentives - income relative to similar professionals employed in the same country.

\begin{tabular}{|c|c|c|c|c|}
\hline \multirow{3}{*}{$\begin{array}{l}\text { INSTITUTE } \\
\text { URF }\end{array}$} & \multicolumn{4}{|c|}{ Income of comparable professionals relative to research staff $(+/-\%)$} \\
\hline & \multirow{2}{*}{$\begin{array}{c}\text { Private Sector } \\
+100 \%\end{array}$} & \multicolumn{2}{|c|}{ Public sector comparison } & \multirow{2}{*}{$\begin{array}{l}\text { NGO } \\
+75 \%\end{array}$} \\
\hline & & $-10 \%$ & Non-Res. Civil service & \\
\hline IRAD & - & Parity & University & $+150 \%$ * \\
\hline DSCHANG & $+100 \%$ & $-30 \%$ & Non-Res. Civil service & $+35 \%$ \\
\hline IDEFOR & $+200 \%$ & $-50 \%$ & Non-Res. Civil service & - \\
\hline IRET & $+125 \%$ & $-50 \%$ & Non-Res. Civil service & $+80 \%$ \\
\hline FORIG & $+80 \%$ & $-15 \%$ & Non-Res. Civil service & $+500 \%$ * \\
\hline IRNR & $+175 \%$ & Parity & Non-Res. Civil service & Parity \\
\hline FRIN & $+300 \%$ & $-50 \%$ & Non-Res. Civil service & $+150 \%$ \\
\hline UIBAD & $+500 \%$ & Parity & Non-Res. Civil service & $+500^{*}$ \\
\hline
\end{tabular}

'Non-Res.' = Non-research.

$+500 \%=$ employee of other organisation receives six times the salary of the respondent; $50 \%$ implies other employee receives half the salary of the respondent.

* = Specific reference to an international NGO, e.g., TROPENBOS. 


\section{Non-salary incentives}

All institutions differ in their capacity to reward their employees with benefits other than salaries. A variety of non-salary incentives were examined in terms of their frequency of use and effectiveness in stimulating research efficiency. They include:

- opportunities for professional training;

- prospects for promotion;

- duty travel to other countries;

- award of additional research funds;

- long service awards;

- sabbatical leave; and

- transport allowances.

Few institutions deploy all of these incentives so the indicator score for each institution is calculated on the basis of the type of incentives it is currently using.

As research becomes more client-driven or marketoriented, the institutions will have to increase their level of autonomy without compromising national or regional research priorities. This will tend to increase their capacity to reward, retain and make better use of their staff. In addition, it will increase the speed with which decisions are made and this can lead to overall improvement in research efficiency and reduce dependency on government funding.

As noted by Gilbert et al. (1994), creativity is one of the ingredients of research that distinguishes it from many other occupations, particularly those in the public sector. Creativity in institutions is a product of skill levels, opportunities, low staff turnover and motivation. All these attributes are present at relatively low levels in many of the institutions surveyed. An increase in the level of institutional autonomy would most likely make the greatest contributions to raising levels of creativity.

\subsection{Published output}

Published output across the survey sample is extremely variable (Table 13). For example between 1993 and 1996 IDEFOR had an average annual publication rate per staff member of almost five. In Benin there were no reported publications during this period. The Francophone institutes of IRAD and IDEFOR seem to be highly productive in terms of total published research outputs, however FRIN and FORIG feature second and third respectively in the indicator ranking because of higher proportions of refereed publications in the total published outputs. University of Dschang, University of Ibadan and IRNR in Ghana have low research output indices, however since these organisations have a dual teaching and research mandate this is to be expected. The definition of what constitutes a 'publication' was open to various interpretations, whereas 'publication in a refereed journal' is a much more specific definition.

\subsection{Strengths, weaknesses, opportunities and threats}

The survey instrument provided an opportunity for senior officials in each institution to characterise institutional 'strengths', 'weaknesses', 'opportunities and 'threats'. This information is presented for each institution in Annex 5. The trends observed across institutions are discussed below.

Table 13. Research outputs by institution for the period 1993-1996.

\begin{tabular}{|c|c|c|c|c|c|c|c|c|}
\hline INSTITUTION & Publications & 1993 & 1994 & 1995 & 1996 & $\begin{array}{c}\text { Period average/ } \\
\text { res. staff }\end{array}$ & $\begin{array}{c}\text { Total scientific } \\
\text { staff }\end{array}$ & $\begin{array}{c}\text { Indicator } \\
\text { value }^{a} \\
\end{array}$ \\
\hline \multirow[t]{2}{*}{ URF } & Total & - & - & - & - & 0.0 & 4 & 0.0 \\
\hline & Refereed & - & - & - & - & & & \\
\hline \multirow[t]{2}{*}{ IRAD } & Total & 20 & 22 & 25 & 30 & 2.5 & 14 & 4.1 \\
\hline & Refereed & 5 & 7 & $12^{*}$ & $15^{*}$ & & & \\
\hline \multirow[t]{2}{*}{ U.'Dschang } & Total & 2 & 2 & 4 & 3 & 0.25 & 11 & 1.3 \\
\hline & Refereed & 1 & 1 & 3 & 2 & & & \\
\hline \multirow[t]{2}{*}{ IDEFOR } & Total & 120 & 108 & 90 & 80 & 4.9 & 20 & 7.9 \\
\hline & Refereed & 14 & 14 & 13 & 13 & & & \\
\hline \multirow[t]{2}{*}{ IRE'T } & Total & 2 & 2 & 3 & 4 & 0.3 & 9 & 1.6 \\
\hline & Refereed & 1 & 1 & 2 & 3 & & & \\
\hline \multirow[t]{2}{*}{ FO'ŌIG } & Total & 16 & $2 \overline{8}$ & $6 \overline{9}$ & 33 & 0.94 & 39 & 4.3 \\
\hline & Refereed & 6 & 11 & 17 & 12 & & & \\
\hline \multirow[t]{2}{*}{ IR $\bar{R} \overline{N R}$} & Total & - & $\overline{1}$ & $\overline{1}$ & 2 & $0 . \overline{12}$ & 8 & 0.6 \\
\hline & Refereed & - & $=$ & - & 2 & & & \\
\hline \multirow[t]{2}{*}{ FRIN } & Total & 48 & $3 \overline{7}$ & 57 & 38 & 1.1 & 42 & 4.6 \\
\hline & Refereed & 14 & 2 & 7 & 7 & & & \\
\hline \multirow[t]{2}{*}{ U.Ibadan } & Total & 17 & n.a. & n.a. & n.a. & 0.32 & 13 & 1.7 \\
\hline & Refereed & 11 & n.a. & n.a. & n.a. & & & \\
\hline
\end{tabular}

Notes: In some cases data was derived from annual reports and research records, in others figures were not verified.

$a=$ Indicator value as derived in Annex 2 and set out in Annex 1.

* $=$ Submitted, some accepted.

n.a. = data not available. 


\subsubsection{Strengths and weaknesses}

With the exceptions of IDEFOR in Côte d'Ivoire and IRET in Gabon all of the institutions considered their staff to be well trained. Institutional experience and reputation were mentioned as strengths by some of the older and larger institutions. The condition of research facilities was often considered as a weakness, however, FORIG with newly constructed facilities cited this as a strength. The most commonly cited weaknesses were associated with a lack of financial resources and loss of staff due to an inability to pay competitive salaries. Inadequately equipped research facilities or a lack of research support staff were also frequently reported. Surprisingly, no institutions commented on the presence or absence of collaborative research arrangements as either a strength or a weakness despite this factor being identified in numerous capacity-related studies and initiatives.

\subsubsection{Opportunities and threats}

A number of institutions saw new funding opportunities for research as a result of increased awareness of forestry and environmental issues and others perceived possibilities of responding to this interest through the provision of consultancy services. Emerging private sector markets for forest-related research were mentioned by IRNR and FORIG in Ghana and by IRAD in Cameroon. The University of Dschang saw the implementation of a new forestry law as a pecuniary opportunity. IRNR and FORIG in Ghana and FRIN in Nigeria perceived the establishment of new research/ teaching organisations and environmental NGOs as threats (rather than as opportunities for collaboration). Declining standards of living due to financial weakness were also perceived as a threat by University of Ibadan, IRNR, University of Dschang, and FORIG.

\section{Conclusions and Recommendations}

The conclusions are presented firstly with respect to each of the indicators of research capacity used in this study and, secondly, in a more general context. Recommendations are presented in the form of key issues for consideration by the actors involved in research capacity-building initiatives.

\subsection{Conclusions}

\subsubsection{Human resources}

- Over two-thirds of the forestry and related research manpower in the West and Central African region is trained to the level of M.Sc. or Ph.D. and with at least four years of experience after obtaining these academic qualifications. The average number of researchers per institute is lower than that observed in the SADC survey.
- Nigeria, Ghana and Côte d'Ivoire have the highest numbers of qualified and experienced research staff. Francophone countries tend to have researchers that 'learn by doing' rather than obtaining formal university research degrees that is the norm for the Anglophone countries.

- There is an almost total absence of private sector forestry research in all the countries surveyed. Researchers are found largely in the public/ government sector. There is an 'ephemeral cadre' of research staff associated with NGOs or donor projects, often drawing on public sector employees on a shortterm contractual basis.

- Over the period 1993-1996 there was a reduction in staff numbers for IDEFOR and FRIN but a modest increase for FORIG. Staff numbers for other institutions in the survey sample have remained relatively constant. These figures do not seem consistent with the perceived 'weaknesses' and 'threats' that the institutions cite with respect to loss of staff. Our data, however, do not capture staff turnover.

- Research staff frequently engage in consultancy contracts in an individual capacity. It is uncertain to what extent these activities divert research efforts from the institutional mandate, however, it exacerbates the problems of coordinating research efforts.

\subsubsection{Financial resources}

- The findings mirror the situation observed in the SADC study. There is considerable annual variation in research funding, and it is common for the level of funding to cover little more than basic salaries and operating costs.

- Institutes are frequently subjected to the adverse effects of economic externalities like national currency devaluation. Strategies to minimise exposure could be improved.

- The absence of a strong private sector in forestry, other than for logging, is indicative of the limited market for contract research in West and Central African. In Ghana, the developing private sector forestry market may offer some additional opportunities for research funding in that country. More generally, and in conformity with the findings from the SADC survey, national governments and the international community continue to be the dominant source of research funding for the institutions of West and Central Africa.

\subsubsection{Adequacy of research capacity to support decision making}

- For research to play a role in decisions on resource policy there must be effective linkages between researchers and decision makers. Research institutes in West and Central Africa allocate a very small percentage of their budgets to developing interactions 
with, or transferring information to, user groups. The type of user group varies both within and between institutions. Most commonly the institutions refer to development projects, NGOs, extension services, local communities and private companies.

- There appears to be little linkage between research and national/sub-national policy debates. It is obvious that some of the greatest impacts on natural resource management will develop from influences exerted on the policy process. The forestry research communities in the region are generally not well connected with, or do not specifically target, policy makers or 'influential' people participating in national policy processes when they disseminate research findings. Research activities that have a definite policy orientation are almost non-existent among the 'traditional' forestry research institutes.

\subsubsection{Linkage between the research institutions and other relevant institutions}

- Interactions between institutions within the national forestry research systems are frequent and are perceived as being moderately or very beneficial. Linkages with 'non-forestry' research institutions are less common and forestry research is still largely focused on 'traditional' forestry research issues and approaches.

- Interactions with educational institutions within countries were frequent (in over $66 \%$ of centres) and perceived by all as being beneficial to the research process. Contacts with educational institutions in other countries in the region were absent.

- Interactions with educational institutions in countries outside the region were common and always with institutions of high research capacity in Europe or North America. This pattern was also observed in the SADC survey where contacts with foreign institutions, particularly those from countries outside the region were viewed as the most beneficial. Most of the linkages with foreign educational institutions outside the region are related to post-graduate training of researchers. The frequency is most likely connected with the limited training possibilities available elsewhere in the region, which would also explain the low level of 'educational' interactions between countries in the region.

- The proportion of staff time and budgets associated with transfer of research results to user groups is, with the exception of IRET, generally low.

\subsubsection{Adequacy of resources to support research}

- Buildings, laboratories and field stations show considerable variation but can generally be described as adequate or poor. There is a notable absence of good computing and electronic information services. This is coupled with generally poor library facilities with the result that researchers work in an information-poor environment. This frequently has negative effects, not least of which is undertaking research that needlessly duplicates previous efforts elsewhere.

\subsubsection{Main constraints to research and capacity building}

The present study confirmed the continuation in the region of six major constraints to effective performance and utilisation of research in Africa identified by the African Academy of Sciences (1994). These were:

- insufficient collaborative research - inferred from the level of interactions between institutions, and the low level of research outputs that have been jointly produced;

- poor research and development linkages - indicated by low level of interactions with user groups;

- inadequate flow of information and access to scientific literature - confirmed by weak interactions between institutions, especially those poorly resourced, and the unsatisfactory state or absence of library facilities;

- poor research-education linkages - indicated fairly weak interactions between research and educational establishments in the respective countries despite any contacts being viewed as moderately beneficial;

- low sustainability of research programme support low level of research funding from local sources and the concomitant dependence on donor funding for research; and

- lack of coordination with donors.

\subsection{Recommendations}

While there are numerous publications that emphasise the need for capacity building in the region and in Africa more generally, there seems to be a lack of clarity in terms of the most effective means of addressing the problem. It is relatively easy to discern the symptoms of a suboptimal research institute and relatively easy to ameliorate them on an individual basis, but it is far harder to treat the underlying causes.

We observe that most capacity-building initiatives tend to have a 'supply'-side bias. They do not place enough emphasis on creating dynamic (learning) mechanisms for balancing 'demand', in terms of those problems where research can make a difference, within the context of the 'supply' of vital components to their solution.

Most studies relating to research capacity development also show this supply-side bias. They are coupled with vague calls for increased donor, government and/or institutional coordination and collaboration. Development programmes that do focus on capacity-building goals all too often emphasise the 'actors' not the 'systems' within which they operate. Calls for greater allocation of 
financial resources to be spent on institutional infrastructure and staff training and development are the norm. In this respect, capacity building tends to address symptoms rather than causes and assumes that the main problems and constraints only relate to a shortfall in the quantity/quality of research rather than the match between the available supply and the actual demand. Successes are often claimed, however, because the measures of success are frequently defined in terms of input-oriented criteria: how many staff were trained; how many computers does an institute now have?

The design and planning of capacity-building projects must replace reductionist approaches that regard each institution as an entity in isolation and assume that a predetermined set of 'solutions' can be applied across the board. Very seldom do capacity-building projects adopt an approach that advocates strengthening by adaptation to existing structures and systems.

Important research (and capacity-building) problems at regional, national or local scales frequently 'cut across' the traditional national governance apparatus of ministries of finance, education, agriculture and forestry for example. Responsibility for the solution of these problems, however, is often artificially compartmentalised within these sectors. Similarly, donor-funded interventions are also frequently financed and implemented on a sectoral basis. Rarely do debates at a national level consider demand for research across sectors, and even more rarely are the purposes (potential impact) of research clearly articulated in terms of their intended effects on national policy objectives, e.g., to reduce poverty maintain environmental goods and services or contribute to local and national economies

The challenge is to promote a dynamic vision of capacity development that acts in concert with broader-based capacity development initiatives both within and outside the 'traditional' forestry sector. In short, attempts at capacity building focused at the institutional level will only yield a cumulative impact. Capacity-building activities aiming to improve efficiency of the research system offer the possibility of yielding 'systemic' impacts, i.e., results that have a multiplier effect in terms of efficient allocation of resources.

Gakale et al. (1996) made several recommendations in relation to strengthening research capacity:

- establishment of clear national and regional priorities for research;

- sensitising treasury and ministry of finance staff on the need for increased allocation of resources for research - a policy dialogue with policy makers;

- regional collaboration in research in order to avoid duplication of efforts and to share findings from research;

- rationalisation of ongoing activities;

- looking for alternative funding mechanisms;

- collecting evidence of the impact of past research to make a case for an increased funding allocation to ANR sectors; and

- better linkages and collaboration with IARCs to ensure the efforts are complementary and that IARCs priorities reflect the national and regional priorities.

While we agree with these recommendations we see an additional need to set them in a systems context. Adopting a 'systems approach' to the capacity-building process can help in the design and implementation of interventions that will have a large and long-term impact. Capacitybuilding activities must be seen as interventions in a dynamic system not as 'one-off' fixes to static problems. The key recommendation that we advocate is for capacity-building initiatives to focus much more on developing 'adaptive' processes that continually strive to match the 'supply' side of research to the most important problems, constraints and issues (the demand side). Mechanisms that aim to improve the link between research supply and demand need to incorporate perspectives from research user groups. We see a need for research institutions, national governments and regional research coordinating bodies to initiate 'market research' activities (in the corporate sense of the term) at local, national and regional levels. 


\section{References}

African Academy of Sciences 1994 Observations and recommendations. First International Symposium: Supporting Capacity Building in Forestry Research in Africa, Nairobi, Kenya, 28 June-1 July 1994.

African Development Bank 1994 African Development Bank forest policy and strategy for lending to forestry development programmes in Africa. African Development Bank, Abidjan.

Bengston, D.N., Gregersen, H.N., Lundgren, A.L. and Hamilton, L.S. 1988 Forestry research capacity in the Asia-Pacific region. Occasional Paper No. 6. East-West Environment and Policy Institute, Honolulu.

Burley, J., Armitage, F.B., Barnes, R.D., Gibson, G.L., Hardcastle, P.D., Huguet, L., Plumptre, R.A. and Wood, P.J. 1989 Forestry research in Eastern and Southern Africa. Tropical Forestry Papers No. 19. Oxford Forestry Institute, Oxford.

Food and Agriculture Organization of the United Nations (FAO) 1995 Directory of forestry research organisations. FAO, Rome.

Gakale, L.P., Ndunguru, B.J. and Anandajayasekeram, P. 1996 SCCAR's comments/position on the Outline Action Plan to strengthen the NARS-CGIAR partnership. Paper presented at the Sixteenth SPAAR Plenary Session, Kampala, Uganda, February 1996.

Gilbert, E., Matlon, P. and Eyzaguirre, P. 1994 New perspectives for vulnerable institutions: agricultural research systems in the small countries of West Africa. Briefing Paper No. 14. ISNAR, The Hague.

Jaycox, E. 1993 Capacity building: the missing link in African development. Address to African-American Institute Conference, Reston, Virginia, May 201993.

Kio, P. 1990 Forestry research in the Africa region. FAO Experts Meeting on Forestry, 4-6 December 1990. FAO, Rome.

Kowero, G.S. and Spilsbury, M.J. 1997a Capacity for forestry research in the Southern African Development Community. CIFOR Occasional Paper No. 11. URL: http://www.cgiar.org/cifor/publications/occpaper/ occpaper11.html.

Kowero, G.S. and Splisbury, M.J. 1997b Evaluation of forestry research capacity in Eastern and Southern Africa. Journal of World Resource Management 8: 159-82.

Mergen, F, Evenson, R.E., Judd, M.S. and Putnam, J. 1988 Forestry research: a provisional global inventory. Economic Development and Cultural Change 37: 149-71.

Odera, J. and Pape, S. 1994 Forests and biodiversity: a research support programme for Sub-Saharan Africa.
Paper presented at First International Symposium: Supporting Capacity Building in Forestry Research in Africa, Nairobi, Kenya. 28 June-1 July 1994.

Pardey, P.G., Roseboom, J. and Anderson, J.R. (eds.) 1991 Agricultural research policy: international quantitative perspectives. Cambridge University Press, Cambridge.

Ridker, R.G. 1994 The World Bank's role in human resource development in Sub-Saharan Africa: education, training, and technical assistance. The World Bank, Washington, DC.

Sharma N.P., Reitbergen, S., Heimo, C.R. and Patel, J. 1994 A strategy for the forest sector in Sub-Saharan Africa. Technical Paper No. 251, Africa Technical Department Series. Washington, DC. URL: http:// www.worldbank.org/aftdr/findings/english/find18.htm.

Someshwar, S. 1994 Capacity building in World Banksupported forestry projects in Sub-Saharan Africa. Environmentally Sustainable Development Division, Africa Technical Department. World Bank, Washington, DC.

Spilsbury, M.J. and Byron, N. 1996 CIFOR submission to TAC, priorities and strategies for forestry research. Unpublished manuscript

Szaro R.C., Thulstrup, E.W, Bowers, W.W., Souvannavong, O and Kone, I. 1998 Mechanisms for forestry research capacity building. Paper submitted to the International Consultation on Research and Information Systems (ICRIS) Meeting in Gmunden, Austria, 7-10 September 1998.

Technical Advisory Committee of the CGIAR (TAC) 1994 Review of CGIAR priorities and strategies. TAC Secretariat, FAO, Rome.

Technical Advisory Committee of the CGIAR (TAC) 1997 CGIAR priorities and strategies for resource allocation during 1998-2000. TAC Secretariat, FAO, Rome.

Walton, D. 1994 Regional priority setting: report of a roundtable, ISNAR, 18-20 April 1994. Briefing Paper No. 12. ISNAR, The Hague.

World Bank 1996a Special Program for African Agricultural Research (SPAAR): frameworks for action an initial review. Findings, Africa Region No. 64. URL: http://www.worldbank.org/aftdr/findings/english/ find64.htm

World Bank 1996b Ghana: capacity development and utilization initiative. Findings, Africa Region, No 69. URL: http://www.worldbank.org/aftdr/findings/ english/find69.htm 


\section{Additional Literature}

Alvez, E.R.A. 1984 Comments by participants. In: Elz, D. (ed.) The planning and management of agricultural research, 122-23. Proceedings of a World Bank and ISNAR Symposium, Oct. 31-Nov. 10 1983. World Bank, Washington, DC.

Clark, N. 1980 The economic behaviour of research institutions in developing countries - some methodological points. Social Studies of Science 10: 75-93

Cissé, M.K., Sokona, Y. and Thomas, J.P. 1998 Capacity building: lessons from Sub-saharan Africa. Environnement et Développement du Tiers-Monde (ENDA-TM). Enda Energy On-line Documents. URL: http://www.enda.sn/energie/indexpea.htm.

Collinson, M.P. and Tollens, E. 1994 The impact of the International Agricultural Research Centers: measurement, quantification and interpretation. Issues in Agriculture No.6. CGIAR, Washington, DC.

Elz, D. (ed.) 1984 The planning and management of agricultural research. P Proceedings of a World Bank and ISNAR Symposium, Oct. 31-Nov. 10 1983. World Bank, Washington, DC.
FTP/SADC 1994 SADC forestry sector human resources survey 1994. Final report. SADC Forestry Sector Technical Co-ordination Unit (FSTCU), Malawi and FTP International Ltd., Finland.

Ruttan, V.W. 1978 Reviewing agricultural research programmes. Agricultural Administration 5: 1-19.

Southern African Development Community (SADC) 1992 Regional policy and strategy for food, agriculture and natural resources.

Southern African Development Community (SADC) 1992 Forestry research plan for the SADC Region. SADC Forestry Sector Technical Co-ordination Unit (FSTCU), Lilongwe, Malawi.

Schweitzer, G.E. and Long, F.A. 1979 Developing a methodology for assessing the contributions to industrial development of science and technology institutions in developing countries. Final Report to the US Department of State, September, 1979. The Program on Science, Technology, and Society, Cornell University, Ithaca. 


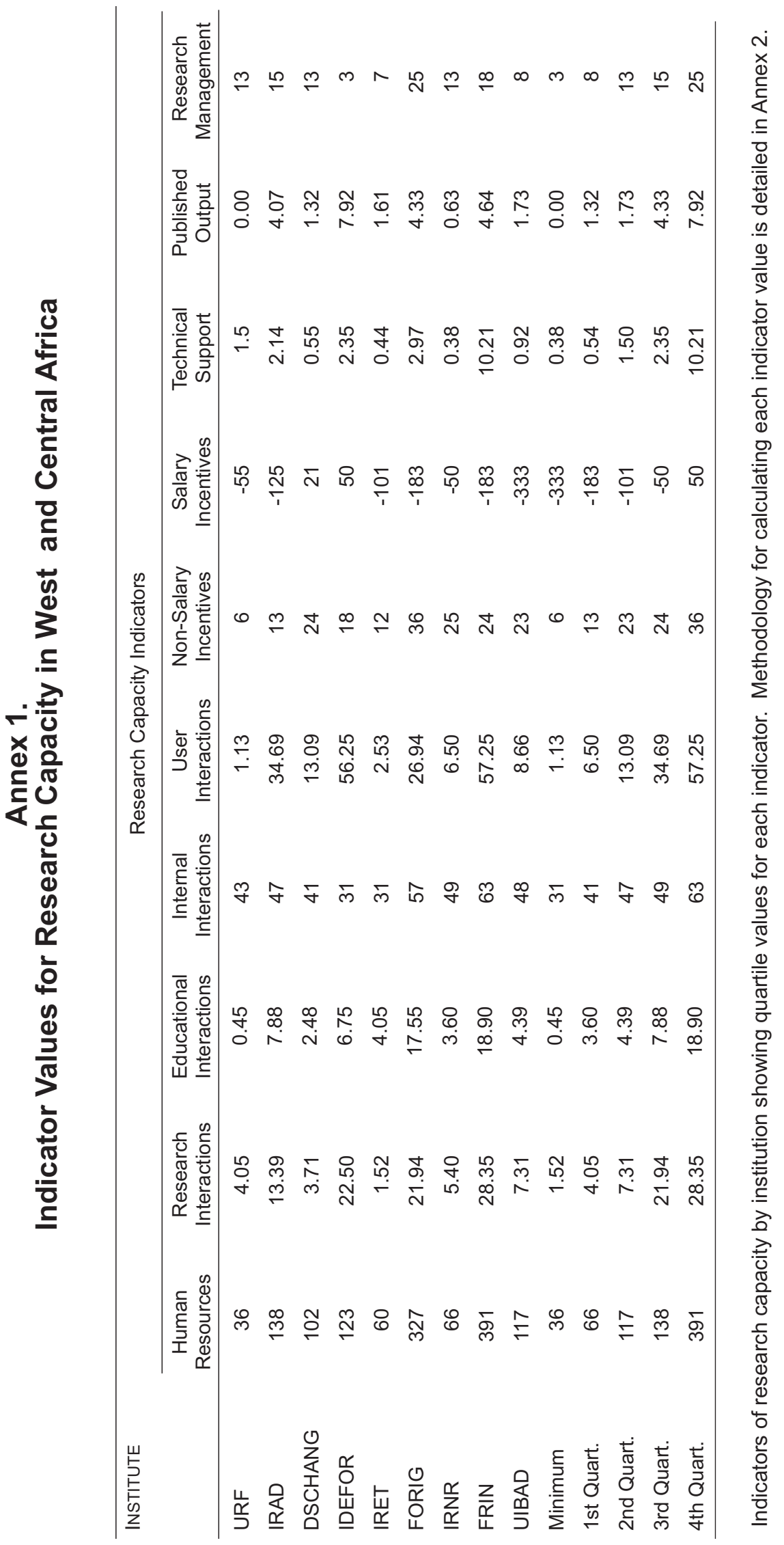




\section{Annex 2. Methodology and Indicators of Research Capacity}

The methodology attempts to capture the most important aspects of research capacity by means of quantitative indicators or proxies. The comparison of indicators between institutions allows determination of the relative research capacities. It does not, however, yield optimum or absolute values. The indicators have the advantage of being simple to understand and the data required can generally be collected quickly and efficiently.

\section{Survey Methodology}

Data collection was largely by means of structured interviews with the heads of forestry research institutions or with senior forestry-related researchers in other organisations. The interviews were conducted informally and the aims and background to the study were explained. In some institutions the full complement of data required was not readily available, e.g., financial information, publications and breakdown of staff by activities or specialty, and these were provided (in most of these cases) at a later date.

The data collected were tailored to the requirements of the methodology for quantification of the following set of indicators, additional qualitative information was captured via further discussion and visits to institutions' facilities and field sites. Bengston et al. (1988) developed a methodology that was modified for the CIFOR research capacity study undertaken in the SADC region. This has been further modified in the light of experience.

Results of the survey are presented as a set of indicator values for each of the institutes. These were processed in a simple spreadsheet, and a graph for each institution was produced showing the normalised quartile values for each of the indicators. The value of each indicator was then plotted against the sample quartile values, thus providing a measure of relative research capacity with respect to the indicators used.

\section{Human resources (HR)}

Effective scientific manpower is one of the most important factors affecting research capacity. Most studies, including Bengston et al. (1988.) rely on total staff numbers to reflect the available resource. In this study the indicator used attempts to reflect staff experience and qualifications.

$$
H R_{i}=\sum\left(G_{j}+2 q_{i}\right)+4 E
$$

where:

$i=i$ th research institution;

$G=$ length of service of the $j$ th staff member: $1=$ less than four years, $2=$ four to ten years, $3=$ over ten years; $q=$ highest qualification of the $j$ th researcher with; $0=$ B.Sc., 1 = M.Sc.; 2 = Ph.D.;

$E=$ total number of expatriate research staff in the institution.

This expression reflects the 'relative worth' of researchers to a research institution, and has been arbitrarily quantified (Table A2.1) with respect to the qualifications and duration of service per researcher within the institute.

Table A2.1. Weightings applied to human resources indicator.

\begin{tabular}{lccc}
\hline \multirow{2}{*}{$\begin{array}{l}\text { Highest } \\
\text { qualification }\end{array}$} & \multicolumn{3}{c}{ Duration of service } \\
\cline { 2 - 4 } & \multicolumn{3}{c}{ years } \\
\cline { 2 - 4 } & $<4$ & $4-10$ & $>10$ \\
\hline Ph.D. & 5 & 6 & 7 \\
M.Sc. & 3 & 4 & 5 \\
B.Sc. & 1 & 2 & 3 \\
Expatriate & 4 & 4 & 4 \\
\hline
\end{tabular}

This 'relative worth' is based on several assumptions that may not adequately reflect reality:

- New recruits to a research organisation are generally assumed to be less effective than longer-serving staff and that the effectiveness of staff increases over time irrespective of the duties performed or previous experience outside the institution.

- Highest qualification is directly proportional to the level of competence in conducting all research-related duties.

- The 'relative worth' of a staff member is independent of the duties performed.

- Expatriates are assumed to have already reached their maximum potential upon entry and, since this category can have a variety of qualifications, the median 'worth' value was adopted.

\section{Indicators for the external environment}

Within the external environment of the institution three indicators were identified. These have remained largely unchanged from the previous survey of the SADC countries, the only modification has been additional detail relating to interactions with institutions in other countries in the region as distinct from interactions with those outside the region:

The study does not consider interactions between the different divisions/departments within individual research organisations. For universities no explicit consideration was given to interactions between forestry faculties/ departments and other university faculties and departments. These relationships do exist and often are 
important in the implementation of collaborative research arrangements, especially because interdisciplinary approaches to research are becoming more common.

\section{(a) Research interactions (RI)}

Scientific interactions with other research institutions are perceived to be instrumental in overcoming the phenomenon of 'research isolation', in addition to facilitating the development and sharing of resources, research methods and findings. Interactions among institutions can help to create the 'critical mass' of scientists required for some tasks; something which individual institutions might not have. They contribute to building confidence among researchers and institutions, and would appear to be a prerequisite for developing national and international collaboration in research. The following indicator quantifies the extent of interactions with other research institutions:

$$
R I_{i}=w(a F+b N+c R+d O)
$$

where:

$i=i$ th research institution;

$F=$ frequency of interaction with other forestry-related research institutions in the same country;

$N=$ frequency of interaction with non-forestry-related research organisations within the same country;

$R=$ frequency of interaction with forestry-related research institutions in other countries in West and Central Africa

$O=$ frequency of interaction with forestry-related research institutions in countries outside West and Central Africa;

$w=$ ratio of the number of research staff in the $i$ th institute to the mean number of research staff per institution across the sample;

$a, b, c$ and $d$ represent the perceived benefits of the interactions defined in $F, N, R$ and $O$ respectively, and may take the following values: $1=$ no real benefit, $2=$ moderate benefit, 3 = high benefit. The benefits were expressed by respondents with respect to the perceived contribution of the interaction to successful conduct of research activities.

The frequency of interaction $(\mathrm{F}, \mathrm{N}, \mathrm{R}$ and $\mathrm{O})$ may take the following values: $0=$ never interacts, $1=$ interactions are occasional., 2 = interactions are frequent.

This indicator includes weighting not used by Bengston et al. (1988). The rationale for the inclusion of a weight is that the total extent of interactions by a research institution is likely to be proportional to the number of research staff able to interact. Thus, the indicator takes into account the frequency of, and benefit derived from, various interactions adjusted by weighting related to the number of research-related staff in the institution.

\section{(b) Educational interactions (EI)}

Interaction with educational institutions is assumed to enhance research capacity in several ways; including training of research staff, exposure to new ideas and, perhaps, access to current literature as well as possibilities for sharing of resources like libraries, laboratories, software, computers and other equipment. The interactions between the institutions surveyed and educational establishments is given by the following expression:

$$
E I_{i}=w(e E+f Q+g S)
$$

where:

$i=i$ th research institution;

$D=$ frequency of interaction with national educational institutions;

$Q=$ frequency of interaction with educational institutions in other countries in West and Central Africa;

$S=$ frequency of interaction with educational institutions in countries outside West and Central Africa;

$e=$ measure of the value of the perceived benefits from the in-country educational interactions (as in RI above);

$f=$ measure of the value of the perceived benefits from interactions with educational institutions in other countries in West and Central Africa;

$g=$ measure of the value of the perceived benefits from interactions with educational institutions in countries outside West and Central Africa;

$w=$ as defined earlier. This weighting is applied for the same reasons as in the $R I$ indicator.

\section{(c) User interactions (Un)}

The leverage obtained from research funding is enhanced if research is 'demand-driven', i.e., a clear need is fulfilled by the research activity. The extent of interaction with users or potential users of research outputs is taken as a proxy for the extent to which research is targeted to potential users. The indicator is based on the premise that 'extent and effectiveness' of interactions can be quantified from the time and money an institution allocates to these activities:

$$
U I_{i}=B+w T
$$

where:

$i=i$ th research institution;

$B=$ proportion, as a percentage, of annual budget associated with technical transfer and extension of results;

$T=$ proportion, as a percentage, of staff time associated with technical transfer and extension of results;

$w=$ as defined earlier. 
One shortcoming of this indicator is the extent to which the percentage of the annual budget allocated to extension activities or interactions with users of research results represents 'double counting' with respect to the percentage staff time allocation, which also features in the indicator. The staff time component has been weighted by the number of staff in the institution as a ratio of the sample mean. Again, the rationale is that total extent of 'user interaction' is the product of mean time per researcher and number of researchers in an institution, in addition to the financial resources available to facilitate transfer of research results.

The indicator has a number of obvious weaknesses:

- It takes no account of the means by which results are transferred to users.

- It does not attempt to assess the relative merits of the different approaches used to transfer research results, like workshops, publications and demonstration trials.

- It does not highlight the extent to which research findings may be transferred by a third party that services the research institution through extension activities.

- It does not capture the extent to which 'user needs' feature in establishing research priorities and activities nor does it capture the extent to which user needs are met by the research output.

These are all important aspects in ensuring that research outputs yield successful outcomes for the targets of research.

\section{Indicators for internal environment}

Four indicators were identified in an attempt to capture the key characteristics of the internal research environment.

\section{(a) Salary and related incentives (SI)}

The monthly disposable incomes of researchers, comprised of net salaries and other monetary benefits, are one of the key factors for the recruitment and retention of well-qualified staff. How researchers fare financially in relation to colleagues with similar qualifications in other institutions in the same country may influence the rate of staff turnover, the development and stability of research programmes, and staff morale in an organisation. The indicator attempts to capture the disparities between the remuneration of researchers in the surveyed organisation relative to similarly qualified professionals in the same country employed by public sector, civil service or non-governmental organisations:

where:

$$
S I_{i}=\frac{\left(H_{i}+I_{i}+J_{i}\right)}{n_{i}}
$$

$H=$ percentage advantage (or disadvantage if negative) in the income (salaries and allowances) for employees with equivalent responsibilities, qualifications and experience in private sector organisations in the same country relative to an employee in the $i$ th institution.

$I=$ as above but reflecting the advantage or disadvantage of civil servant employees relative to employees in the $i$ th institute.

$J=$ as for $H$ above but reflecting the advantage or disadvantage of NGO employees relative to employees in the $i$ th institute.

$n=$ number of observations for the $i$ th institute $(1,2$ or 3$)$.

The interpretation of the results from this indicator requires care. The indicator reflects the within country competitiveness of the institution in terms of salary incentives, not the total remuneration relative to the sample as a whole.

\section{(b) Non-salary incentives (NSI)}

These may be important in increasing the ability of an institution to attract and retain the key resource of wellqualified and highly motivated research workers. Where an institution is not competitive with respect to salary or where tax efficiency becomes and issue, a good incentive scheme may provide sufficient compensation, e.g., housing and transport allowances. The indicator is defined as:

$$
N S I_{i}=\sum r_{j} \cdot R_{j}
$$

where:

$i=i$ th research institution;

$R=$ measure of the frequency with which the various forms of rewards are used: 1 = used occasionally, 2 = used frequently, 3 = always used;

$r=$ a measure of the effectiveness of the rewards in contributing to researcher productivity: $0=$ not effective, 1 = slightly effective, 2-moderately effective, 3 = very effective;

$j=$ types of incentives offered to researchers, which may include peer recognition awards, housing and transport allowances, travel to other countries, career development opportunities, professional responsibility, sabbaticals/internships, consultancies, training, and award of additional research funding.

\section{(c) Internal interactions (II)}

Well managed research institutes are often characterised by the staff at all levels being informed of, and involved in, key research planning and review procedures. Collective 'ownership' of strategies and priorities is an important component of institutional 'research culture'. An effective research institute will actively promote the transfer of research information between different 
categories of staff, leading to improved understanding of mandate and a common sense of purpose. There is an outreach component to the assessment of these internal interactions in that the involvement of research user groups is 'valued' highly. This does not reflect the degree of influence of representatives in the process or meeting, where one would expect the managerial staff to be most important (powerful). It is intended to indicate the extent to which the internal processes or discussions are oriented towards the production of the research outputs that meet the requirements of the intended users.

The indicator is defined as:

$$
I_{i}=\sum_{j=1}^{5}\left(K . H+\sum a_{l}\right)
$$

where:

$K=$ frequency of use of meeting or formal procedure: $0=$ never, $1=$ once a year, $2=$ every six months, 3 = every month, 4 = every week;

$j=$ type of meeting or formal procedure, five types were used: selection of research projects at institutional 'portfolio' level; planning meetings for research at project level; discussion/ monitoring of research progress at 'portfolio' level; and discussion/monitoring of research progress at research project level.

$H=$ benefit derived from the meeting or procedure: $0=$ no real benefit, $1=$ low level of benefit, $2=$ moderate benefit, 3 = high level of benefit;

$a=$ participants in the meeting or procedure of category $l$, where $I$ may be: administrative and support staff, managerial staff, researchers/library and information specialists, and representatives of research user groups, for which $a$ can take the value $1,2,3$ or 6 respectively.

\section{(d) Research management (RM)}

There are many different approaches to the management of research and there is no single 'correct' or 'best' way. Management will always be tailored to the specific challenges, problems and opportunities that are unique to each institution. However, if managerial staff have been diligent in their duties there should be plans and strategies in place that enable an institution to define its niche in the research environment and gauge whether it is making adequate progress in the pursuit of its mandate. Simple documentation relating to the basic functions of management, planning, implementing, monitoring and controlling research activity, can be used as a proxy to gauge the adequacy of research management. This indicator uses a 'scoring checklist' approach to responses provided to the following questions:

\begin{tabular}{|c|c|c|c|}
\hline \multicolumn{2}{|c|}{ Question } & \multirow{2}{*}{$\begin{array}{c}\text { Yes } \\
1\end{array}$} & \multirow{2}{*}{$\frac{\text { No }}{-2}$} \\
\hline 1. & Is there annual financial auditing? & & \\
\hline & $\begin{array}{l}\text { If 'yes' to } Q 1 \text {, is the audit conducted } \\
\text { by an independent organisation }\end{array}$ & 1 & 0 \\
\hline \multirow[t]{3}{*}{2.} & Is there an institutional strategic plan? & 1 & -2 \\
\hline & $\begin{array}{l}\text { If 'yes' to Q2, do all staff have good } \\
\text { access to a copy? }\end{array}$ & 1 & -1 \\
\hline & $\begin{array}{l}\text { If 'yes' to Q2, is the plan more than } 5 \\
\text { years old? }\end{array}$ & -1 & 0 \\
\hline \multirow[t]{2}{*}{3.} & $\begin{array}{l}\text { Is there a Medium-Term Operational } \\
\text { Plan? }\end{array}$ & 1 & -2 \\
\hline & $\begin{array}{l}\text { If 'yes' to Q3, is the plan more than } 3 \\
\text { years old? }\end{array}$ & -1 & 0 \\
\hline 4. & Is there an Annual Operational Plan? & 2 & -2 \\
\hline 5. & $\begin{array}{l}\text { In the selection of projects and } \\
\text { allocation of resources, are all } \\
\text { projects evaluated together? }\end{array}$ & 5 & 0 \\
\hline 6. & $\begin{array}{l}\text { In the selection of projects and } \\
\text { allocation of resources, are projects } \\
\text { evaluated as opportunities arise? }\end{array}$ & 2 & 0 \\
\hline 7. & $\begin{array}{l}\text { Are there documented selection } \\
\text { criteria for research projects? }\end{array}$ & 2 & -2 \\
\hline 8. & $\begin{array}{l}\text { Is there a list of research project } \\
\text { proposals that were rejected? }\end{array}$ & 5 & -2 \\
\hline \multirow[t]{2}{*}{9.} & $\begin{array}{l}\text { Are research progress reports } \\
\text { prepared for active projects? }\end{array}$ & 1 & -2 \\
\hline & $\begin{array}{l}\text { If 'yes' to Q9, is the frequency more } \\
\text { than once per year? }\end{array}$ & 1 & -1 \\
\hline \multirow[t]{2}{*}{10.} & $\begin{array}{l}\text { Are completed research projects } \\
\text { formally evaluated? }\end{array}$ & 2 & -2 \\
\hline & If 'yes' to Q10, always? & 3 & \\
\hline
\end{tabular}

The indicator for each institution is then calculated by summing the responses to all questions.

\section{Technical support (TS)}

Support to scientific staff in terms of technicians and administrative staff is an important research input. The availability of support staff allows researchers to spend less time on technical and administrative matters, thus increasing the effective time for research.

$$
T S_{i}=\frac{S_{i}}{P_{i}}
$$

where:

$i=i$ th research institution;

$S=$ number of technicians in the institution;

$P=$ number of researchers in the institution.

This expression implies that a higher ratio of technicians to researchers is preferable. Optimum levels for each institute are not known nor is the opportunity cost of allocating too many resources to provision of technicians. Results must therefore be carefully interpreted as the institutes that have the greatest number of technicians per researcher may be making inefficient 
use of research funds by allocation of excessive resources to technical support. In addition, in universities, students provide technical assistance to research. This varies considerably and is not captured by this indicator.

\section{Research outputs (RO)}

Research outputs are one of the main 'vehicles' by which an institution makes contributions to its mandate. Increasingly, those organisations that finance research are shifting the emphasis from the production of outputs to the achievement of impacts. Research outputs should be tailored to 'make a difference' in solving particular problems. Outputs of the research process can therefore take a variety of forms to ensure that they have maximum impact and can range from practical resource management guidelines and techniques, to the provision of structured information, e.g., 'policy briefs' to key policy makers in meetings, conferences or workshops. Qualitative information on the broader definition of research output was collected, but the indicator used still relies on published outputs with the assumption there is a proportional relationship between publications (assumed to be the fundamental unit of the research 'message') and the wider range of research outputs. Institutional research output (RO) takes a mean of research outputs over the preceding four years and is expressed in proportion to the number of research staff. The indicator used can be expressed as: where:

$$
R O_{i}=\frac{\sum_{j=1993}^{1996}\left(H_{j}+2 I_{j}\right)}{4} / P
$$

$i=i$ th research institution;

$H=$ total number of publications for the institution in year $j$ ( $j$ taking the values $1993-1996$ );

$I=$ total number of publications for the institution appearing in refereed journals in the year $j$;

$P=$ number of researchers in the institution.

Clearly, the indicator gives an arbitrary weight in favour of published refereed papers that is three times that for un-refereed material. Although the magnitude of the weight is arbitrary, the indicator implies that refereed material has greater 'value'. This is because the dissemination of refereed material is likely to be wider and 'quality control' in the research more reliable, often a key factor in a user's decision to adopt a research finding. The indicator fails to address such aspects of research as:

- the time (scientist year equivalents) required to conduct different kinds of forestry research, e.g., tissue culture experiments versus tree provenance or site selection trials;

- other forms of research output/product e.g. equipment, software and practical techniques that are not readily described in the format of a scientific paper; and

- the effect of interactions of scientists with user groups.

All these are excluded from the indicator although they may represent major research efforts. 


\section{Annex 3. \\ Research Capacity Profiles by Institution}

\section{Chart Interpretation}

The total data set for all institutions was collated by indicator, and divided into quartiles with 16 being the nominal maximum. The graphs below present the value for each indicator in a given institution relative to the range of indicator values in the survey sample. The results are displayed in this way to allow comparison of indicators that have very different absolute values. Thus an indictor value corresponding to the top of the first quartile reflects the maximum value for that indicator in the survey sample, not the value relative to the maximum possible. An indicator value on the boundary of the second and third values corresponds to the median value in the sample, and the bottom of the fourth quartile the minimum value for an indicator in the survey sample (not necessarily the minimum possible value).
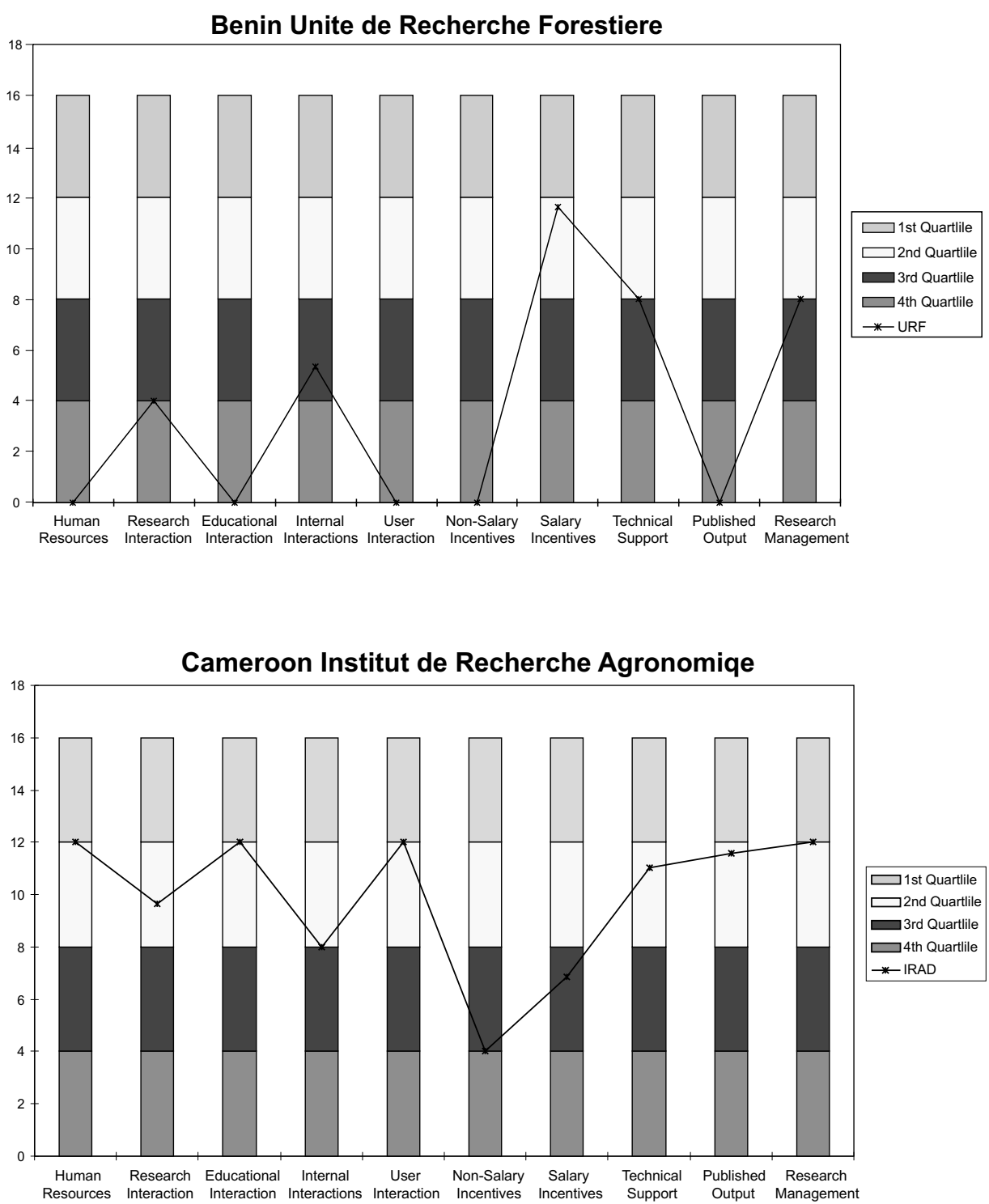

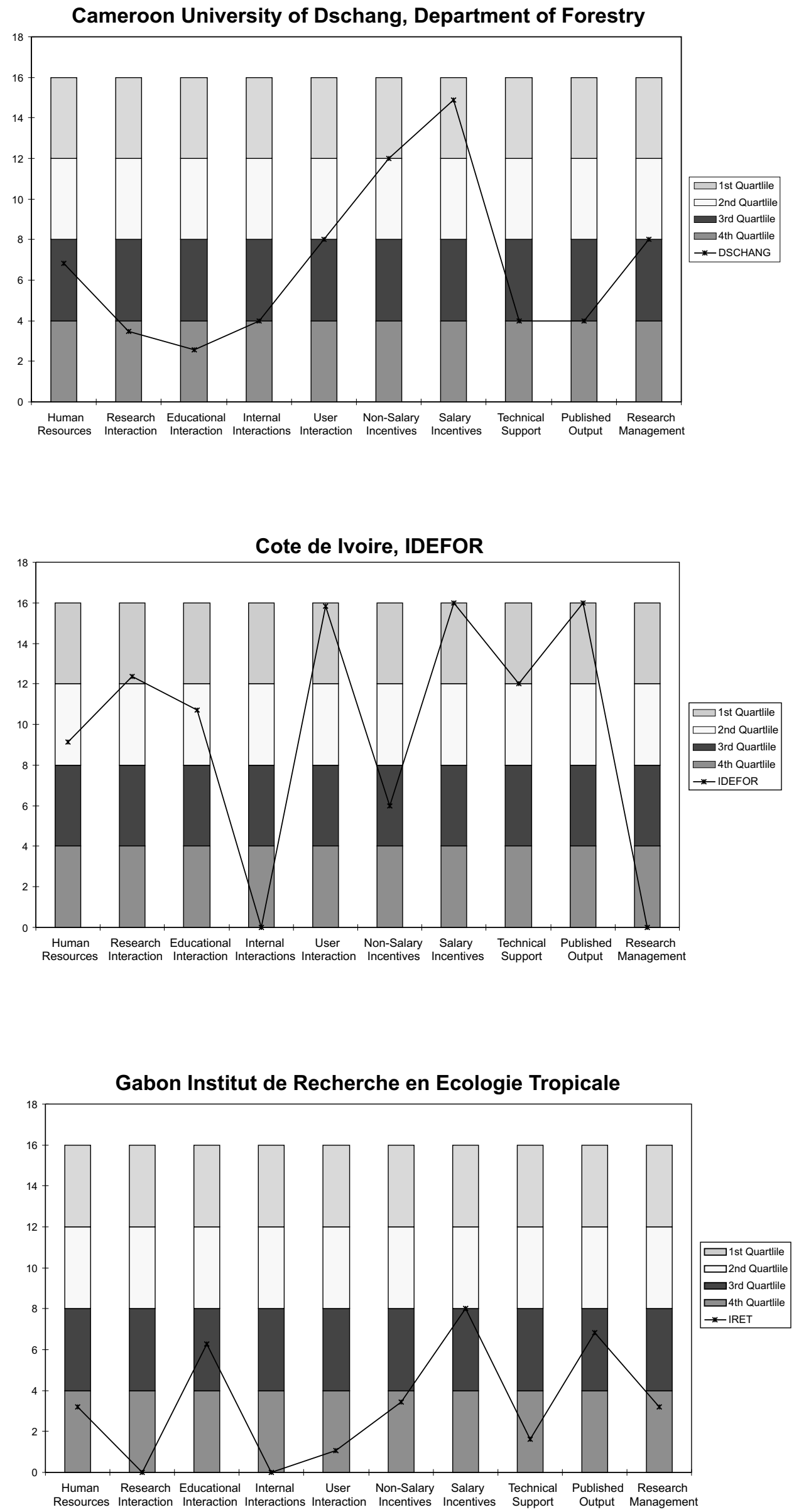
Forestry Research Institute of Ghana

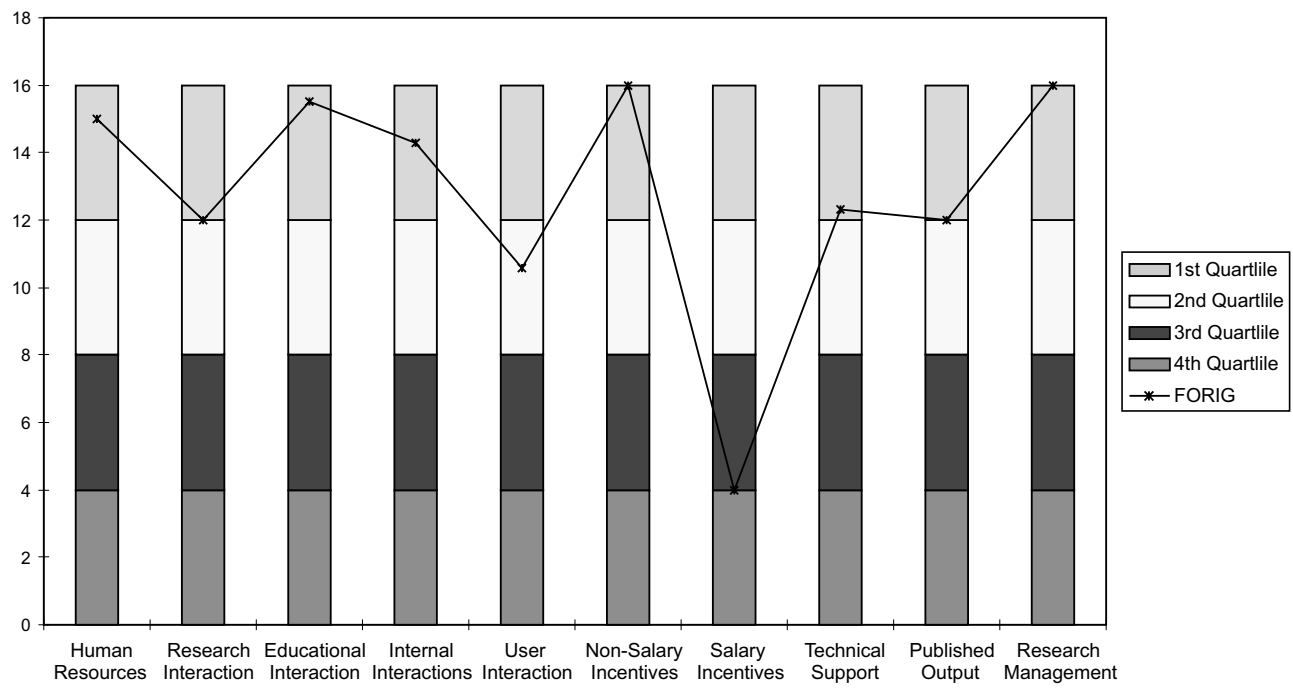

Ghana Institute of Renewable Natural Resources

Dept. of Silviculture and Forest Management

University of Science and Technology, Kumasi

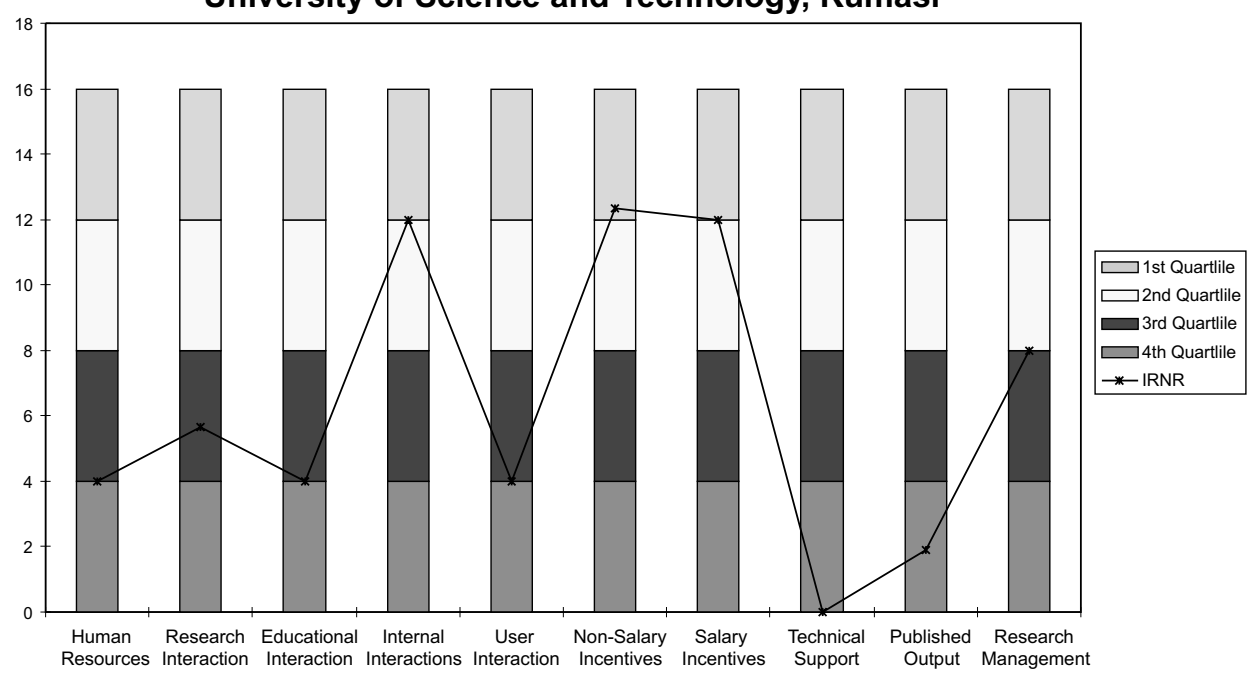

Forestry Research Institute of Nigeria

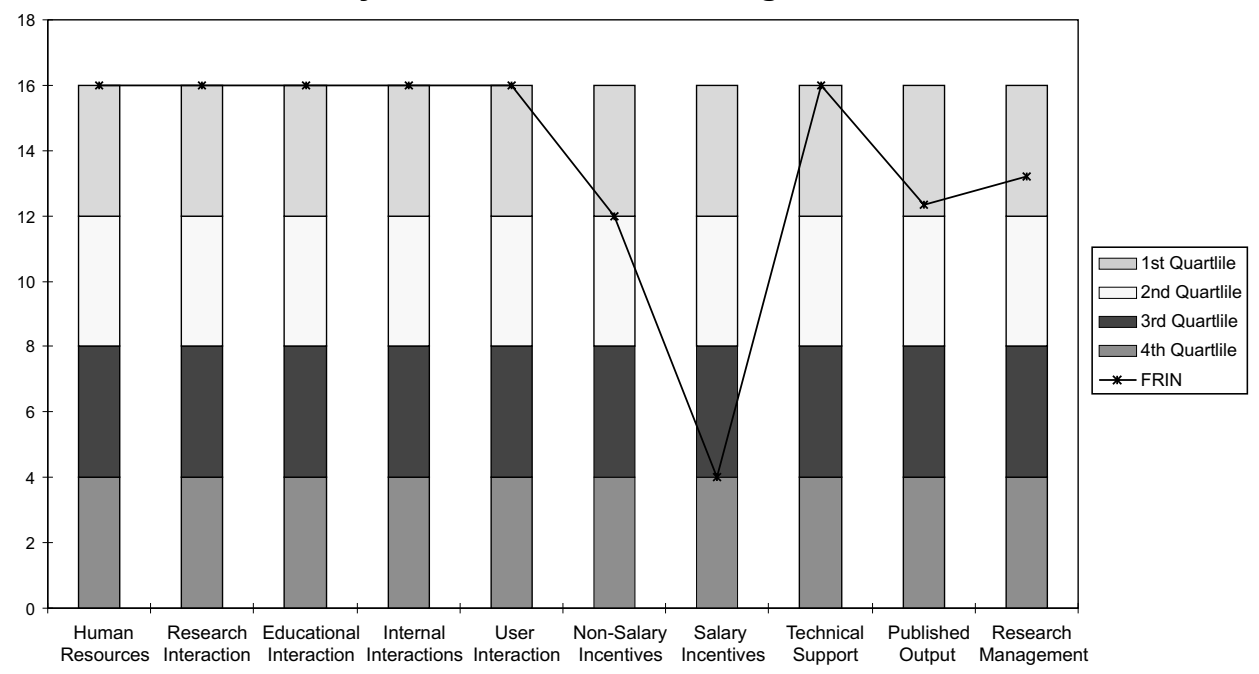


Nigeria, University of Ibadan,

Department of Forest Resources Management

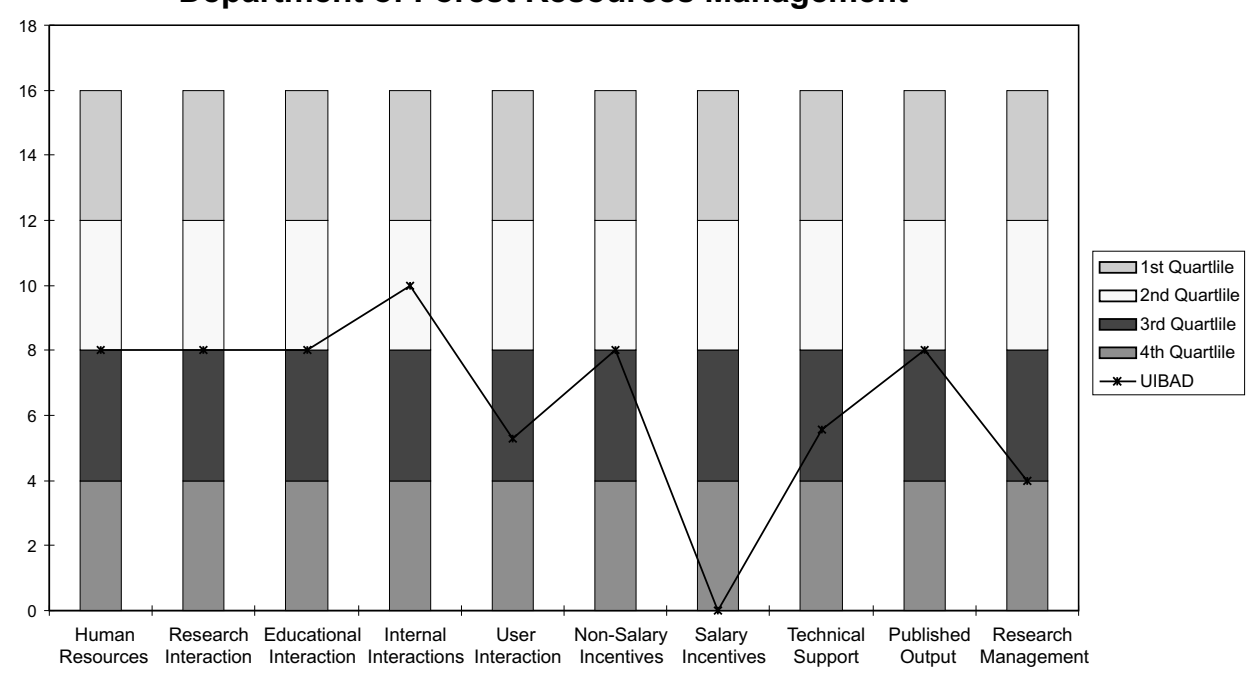


Annex 4.

Research Capacity Indicators Across Institutions
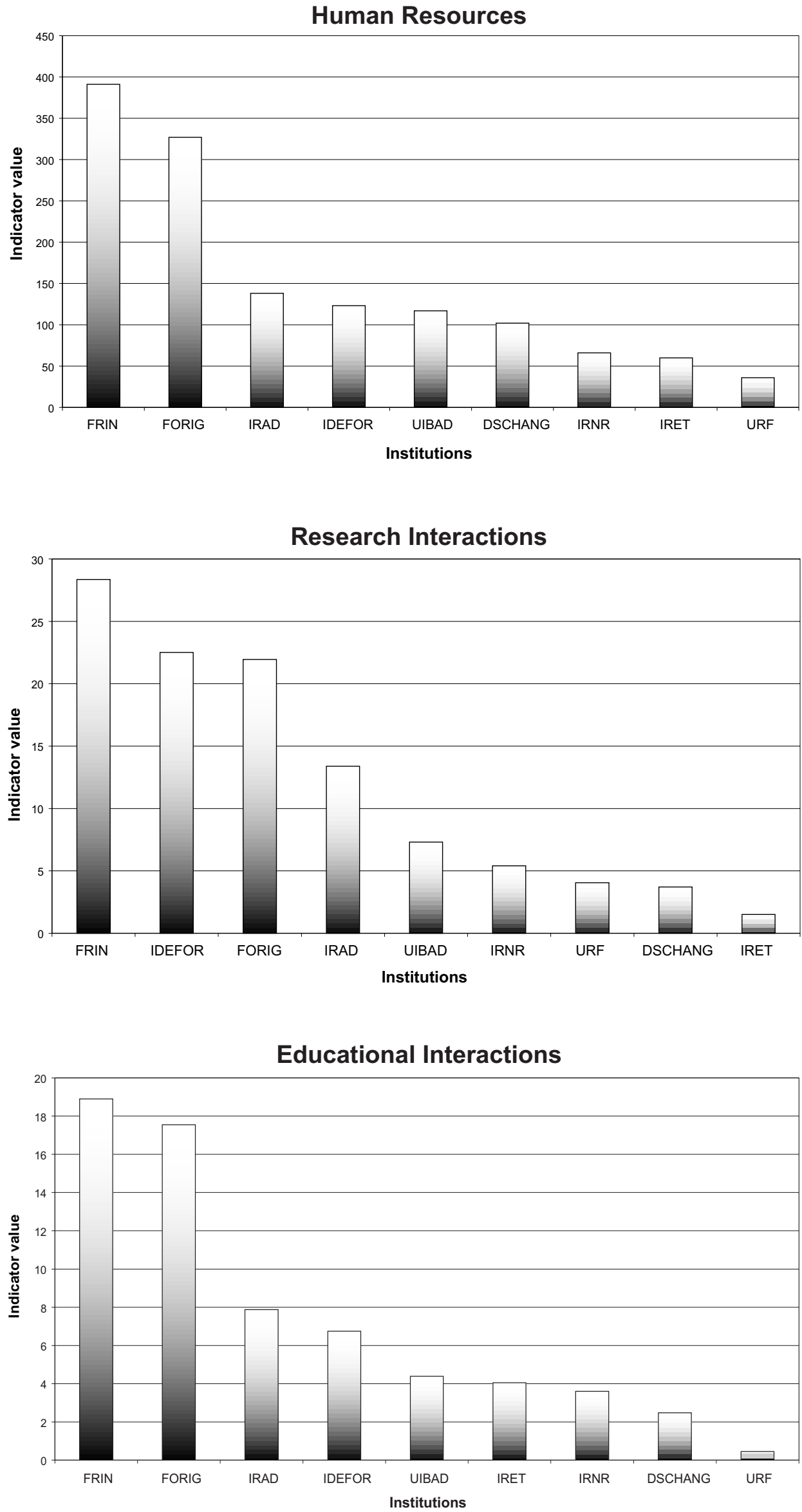
Internal Interactions

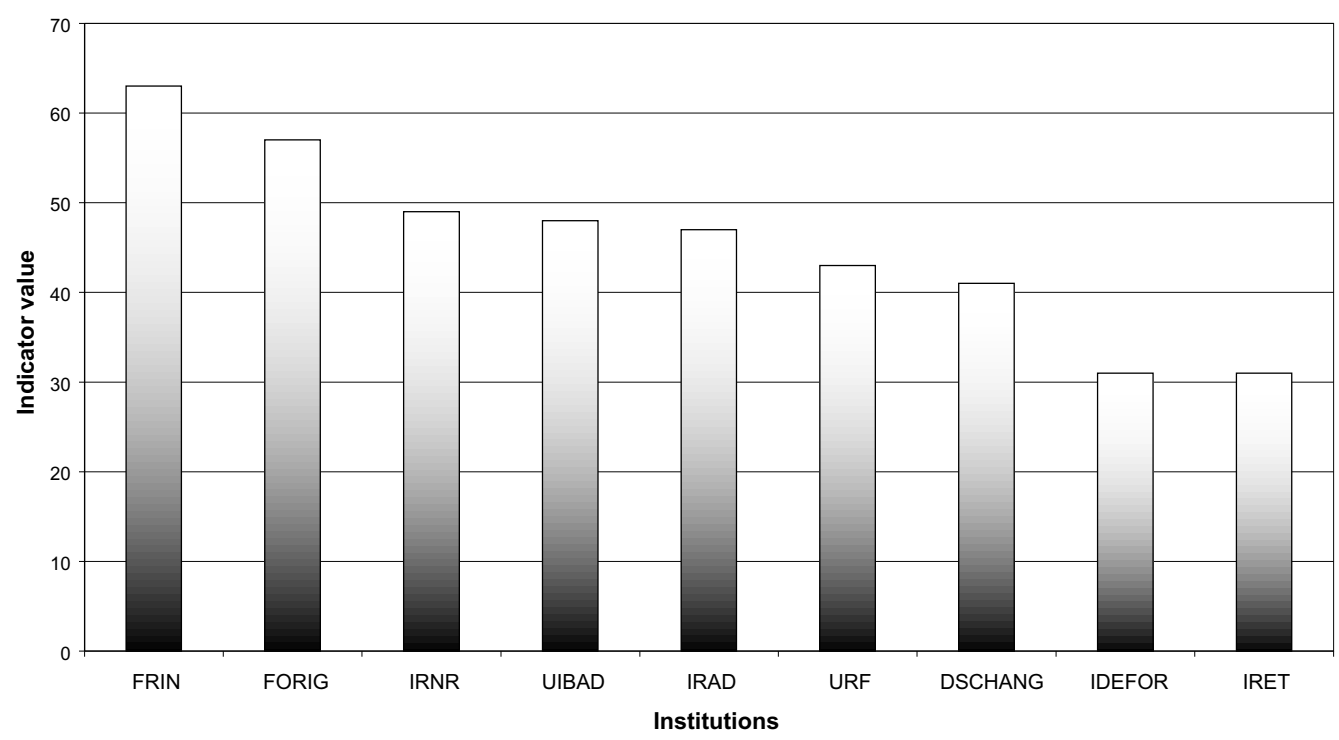

User Interactions

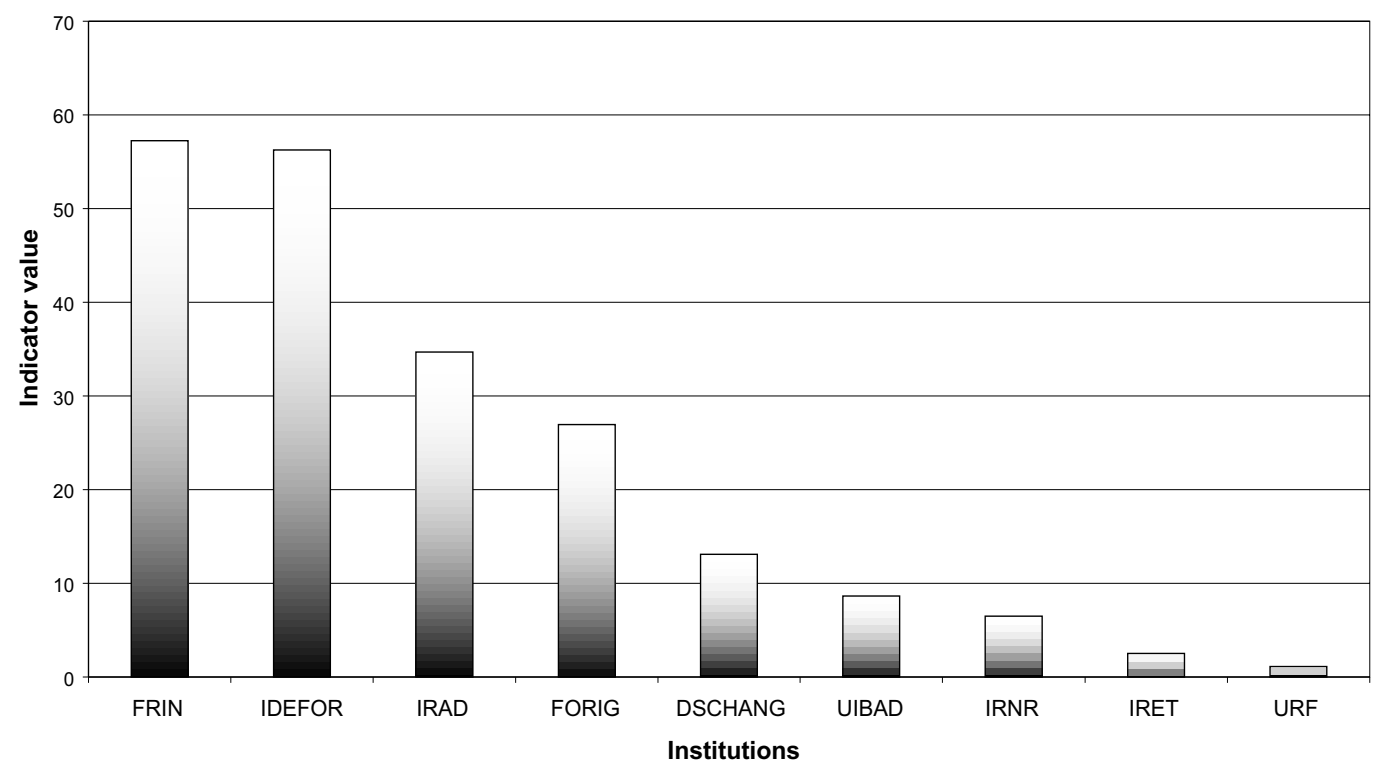

Non-Salary Incentives

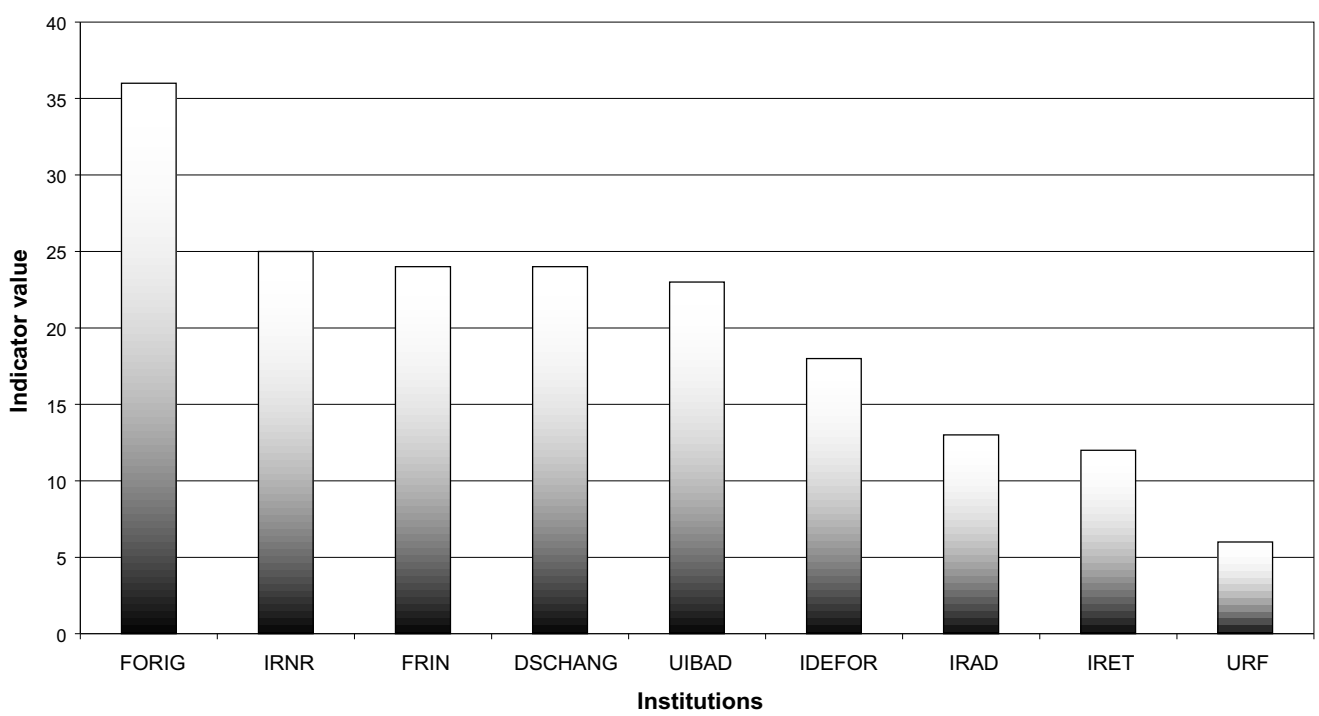


Salary Incentives

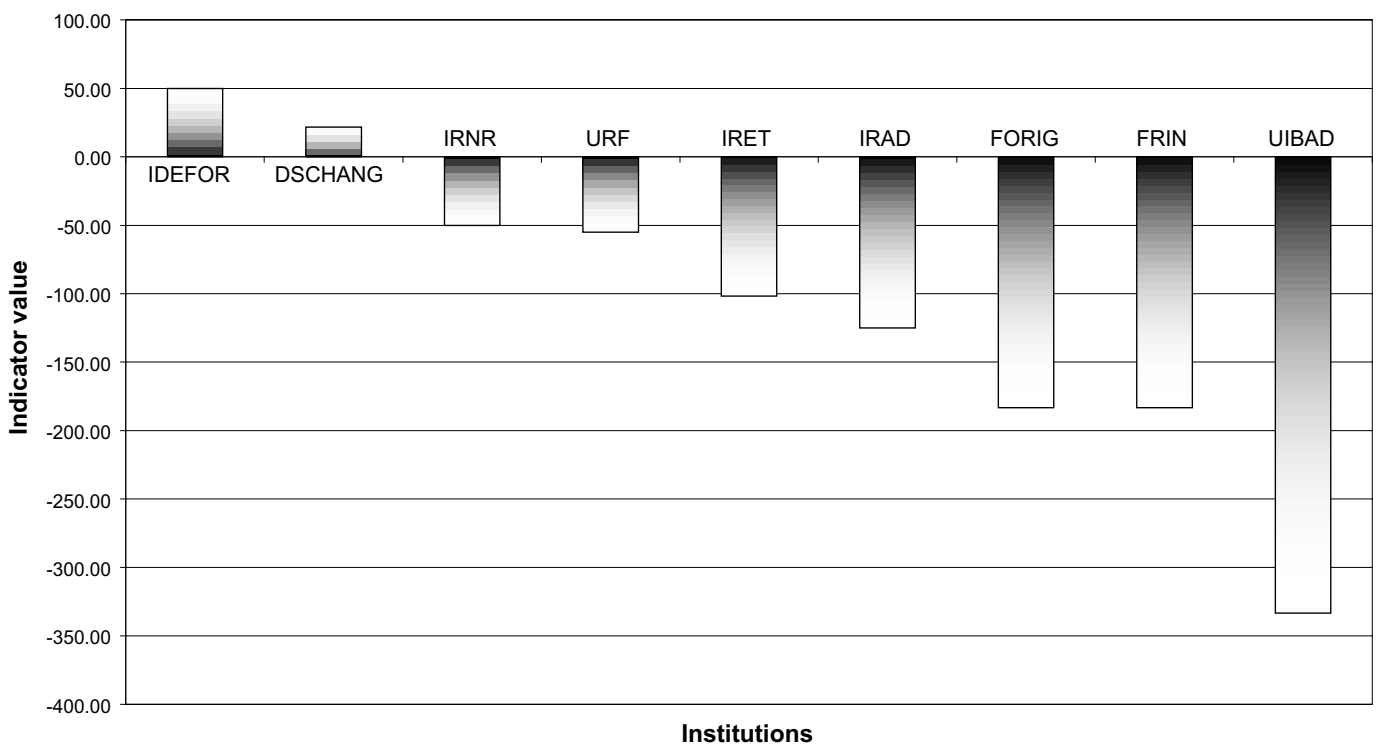

Technical Support

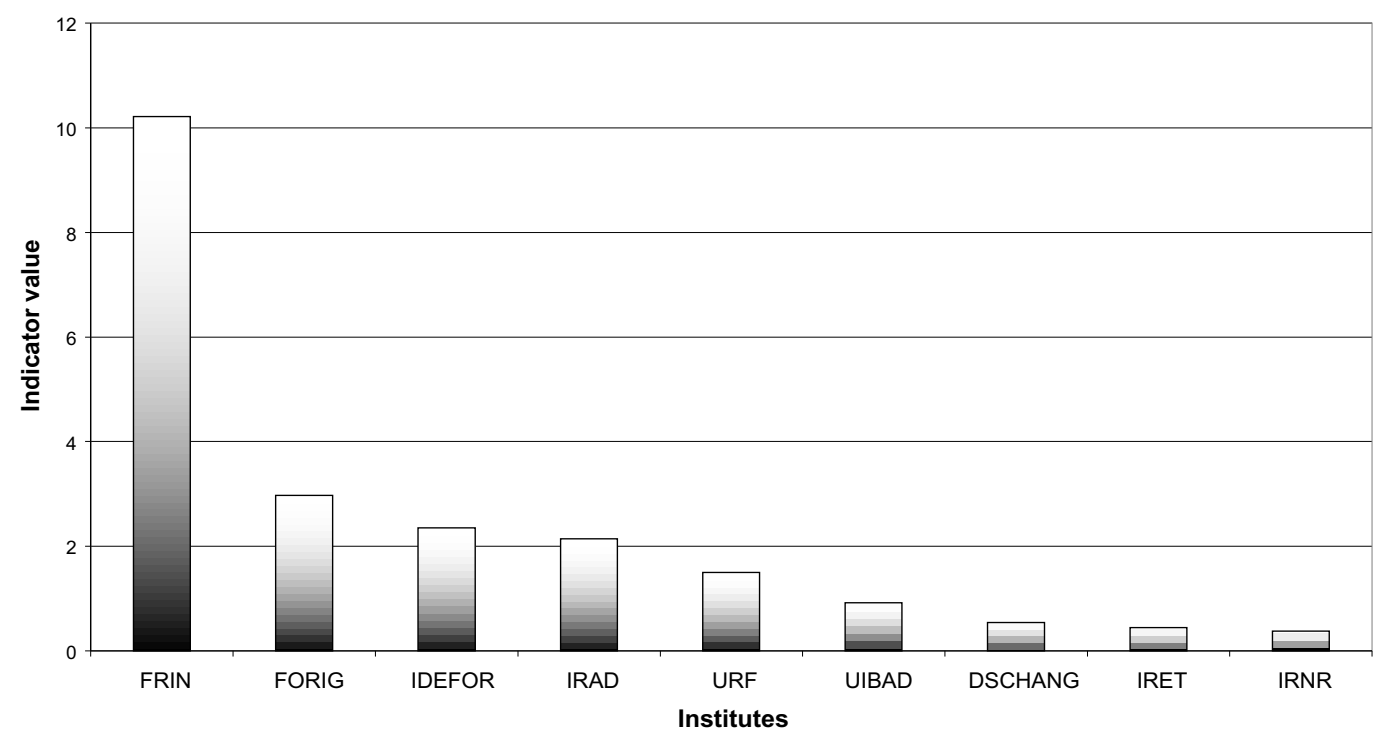




\section{Annex 5. \\ 'Swot' Analysis of Forestry Research Institutions in the West and Central African Region}

\section{Self-Diagnosis: Department of Forest Resources Management, University of Ibadan}

\begin{tabular}{ll}
\hline Strengths & Weaknesses \\
\hline $\begin{array}{l}\text { - Well-trained staff } \\
\text { Good reputation derived from quality research } \\
\text { outputs }\end{array}$ & - Poor funding for education and research \\
\hline Opportunities & Threats \\
\hline $\begin{array}{l}\text { - Sabbatical leave for staff and family overseas at } \\
\text { Government expense (currently restricted) }\end{array}$ & ・ Brain drain \\
\hline
\end{tabular}

Self-Diagnosis: Institute of Renewable Natural Resources, Department of Silviculture and Forest Management, University of Science \& Technology, Kumasi, Ghana

\begin{tabular}{|c|c|}
\hline Strengths & Weaknesses \\
\hline $\begin{array}{l}\text { - Only institute training foresters at the university level } \\
\text { - Key component of the IRNR's core curriculum, } 50 \% \\
\text { of undergraduates opt for forestry } \\
\text { - Highly trained staff to assist field training }\end{array}$ & $\begin{array}{l}\text { - Lack of financial resources is a severe limitation } \\
\text { - Lack of departmental research agenda } \\
\text { - Teaching emphasis reduces time for research } \\
\text { - Inadequate technical support staff }\end{array}$ \\
\hline Opportunities & Threats \\
\hline $\begin{array}{l}\text { - Growing recognition at community, national and } \\
\text { global level of the importance of forestry opens } \\
\text { avenues for collaboration with funding agencies } \\
\text { - Development of private sector forestry opens avenues } \\
\text { for consultancy, research and extension services } \\
\text { - Possibilities of deploying expertise of the Department } \\
\text { as neutral academic unit in developing certification } \\
\text { schemes or Environmental Impact Assessments }\end{array}$ & $\begin{array}{l}\text { - Establishment of Institutions with similar mandates } \\
\text { removes current national 'monopoly' e.g. } \\
\text { Department of Natural Resources of the University } \\
\text { of Development Studies at Tamale and Botany and } \\
\text { Geography Department at the University of Ghana } \\
\text { with respect to forestry extension }\end{array}$ \\
\hline
\end{tabular}

\section{Self-Diagnosis: University of Dschang, Cameroon}

\begin{tabular}{|c|c|}
\hline Strengths & Weaknesses \\
\hline $\begin{array}{l}\text { - Young well-trained staff } \\
\text { - } 20 \text { years of experience in training } \\
\text { - Training students from W \& C Africa }\end{array}$ & $\begin{array}{l}\text { - Infrastructure absent or obsolete, e.g., facilities, } \\
\text { vehicles for field studies } \\
\text { - Economic crisis and poor incentives have led to a } \\
\text { decline in research activity } \\
\text { - Some researchers limited by their administrative } \\
\text { duties }\end{array}$ \\
\hline Opportunities & Threats \\
\hline $\begin{array}{l}\text { - New forestry law promulgated leading to new } \\
\text { funding opportunities at national and regional levels } \\
\text { - Implementation of new law raises questions that are } \\
\text { amenable to research }\end{array}$ & $\begin{array}{l}\text { - Continuing decline in standard of living of } \\
\text { researchers } \\
\text { - After undergoing training some staff are seeking } \\
\text { employment in better paid sectors }\end{array}$ \\
\hline
\end{tabular}




\section{Self-Diagnosis: Forestry Research Institute of Ghana}

\begin{tabular}{|c|c|}
\hline Strengths & Weaknesses \\
\hline $\begin{array}{l}\text { - Unique, sophisticated facilities } \\
\text { - Well-trained cadre of staff in a variety of disciplines } \\
\text { - Good linkages with international forestry and } \\
\text { research institutions } \\
\text { - Fairly well motivated staff }\end{array}$ & $\begin{array}{l}\text { - Inadequate staff in some key areas, e.g., biometrics } \\
\text { - Staff are generally inexperienced } \\
\text { - Inadequate research funding } \\
\text { - Incomplete furnishing of research facility }\end{array}$ \\
\hline Opportunities & Threats \\
\hline $\begin{array}{l}\text { - Not much known about tropical forest ecology } \\
\text { - Growing tertiary wood processing sector } \\
\text { - Growing interest in commercial tree plantations } \\
\text { - Large captive market to develop }\end{array}$ & $\begin{array}{l}\text { - National Forest Department beginning to take on } \\
\text { research } \\
\text { - Competition from Universities } \\
\text { - NGOs taking on research } \\
\text { - Possibility of losing staff to industry and private } \\
\text { organisations }\end{array}$ \\
\hline
\end{tabular}

Self-Diagnosis: Unite de Recherché Forestiere, Institut de Recherché Agronomique du Benin

\begin{tabular}{|c|c|}
\hline Strengths & Weaknesses \\
\hline $\begin{array}{l}\text { - Quality of human resources } \\
\text { - Experience }\end{array}$ & $\begin{array}{l}\text { - Organisation is not operational } \\
\text { - Lack of financial resources } \\
\text { - Lack of marketing policy }\end{array}$ \\
\hline Opportunities & Threats \\
\hline $\begin{array}{l}\text { - Importance of renewable resources and } \\
\text { environmental protection }\end{array}$ & - Poor governance \\
\hline
\end{tabular}

\section{Self-Diagnosis: Institut de Recherché Agronomique pour le Developpement Secteur Environnement et Foret, Cameroon}

\begin{tabular}{|c|c|}
\hline Strengths & Weaknesses \\
\hline $\begin{array}{l}\text { - Highly skilled, highly qualified researchers } \\
\text { - Variety of research plots some with } 20 \text { years of data } \\
\text { - Ample office space } \\
\text { - Housing availability for staff }\end{array}$ & $\begin{array}{l}\text { - Insufficient technicians, lack of incentives } \\
\text { - Donor dependence because of lack of financial } \\
\text { resources } \\
\text { - Lack of transport facilities }\end{array}$ \\
\hline Opportunities & Threats \\
\hline $\begin{array}{l}\text { - Collaborative research proposals to donors especially } \\
\text { EU, ITTO, GEF } \\
\text { - Private sector/industry research contracts, e.g., } \\
\text { UNALOR, CELLUCAM }\end{array}$ & $\begin{array}{l}\text { - Donor-driven priorities } \\
\text { - Brain drain due to poor funding } \\
\text { - Damage to research plots by loggers/farmers }\end{array}$ \\
\hline
\end{tabular}

Self-Diagnosis: Institut de Recherché en Ecologie Tropical, Gabon

\begin{tabular}{ll}
\hline Strengths & Weaknesses \\
\hline $\begin{array}{l}\text { - Research station in the midst of forest with } \\
\text { accommodation and efficient working conditions }\end{array}$ & - Maintenance of the research facilities and equipment \\
\hline Opportunities & Threats \\
\hline $\begin{array}{l}\text { Provide answers to farmers on the sustainable } \\
\text { management of tropical humid forests }\end{array}$ & - Suspicion of foresters \\
\hline
\end{tabular}




\section{Self-Diagnosis: Forestry Research Institute of Nigeria}

\begin{tabular}{ll}
\hline Strengths & Weaknesses \\
\hline - Only research Institute in the forestry sub-sector in & $\begin{array}{l}\text { - Large turnover of trained staff } \\
\text { - Inadequate and irregular release of funds }\end{array}$ \\
$\begin{array}{l}\text { Nigeria } \\
\text { - Highest concentration of forestry specialists in }\end{array}$ & $\begin{array}{l}\text { - Poor remuneration } \\
\text { - Brain drain }\end{array}$ \\
- Nigeria & \\
- Some staff have regular part-time teaching & \\
- Long institutional history and accompanying & \\
attributes of experience & \\
- Outstations are present in all agro-ecological zones & \\
of Nigeria & \\
- Impact of the institute is enhanced by the four & \\
Diploma-awarding Colleges of the Institute & Threats \\
\hline Opportunities & - New organisations and environmental NGOs use \\
- May be broken into smaller Research Institutes in & research results of FRIN and sometimes take over \\
the future & FRIN's role \\
Many research questions relevant to Nigeria remain & - Undue delays in the promotion of deserving staff \\
unanswered & Appointment of Director or Chief Executive \\
- Good opportunities for support from international & \\
funding agencies due to mandate &
\end{tabular}

\section{Self-Diagnosis: Institut des Foréts de Côte d'Ivoire/Departement des Foréts}

\begin{tabular}{ll}
\hline Strengths & Weaknesses \\
\hline $\begin{array}{l}\text { - Existence of law regulating research } \\
\text { - Existence of a Ministry of Scientific Research } \\
\begin{array}{l}\text { - Forest belongs to the state so research permission is } \\
\text { not a problem }\end{array}\end{array}$ & $\begin{array}{l}\text { - Management is highly centralised which has a } \\
\text { negative effect on planning activities }\end{array}$ \\
\hline Opportunities & Threats \\
\hline - None identified & - Financial constraints \\
& - Inadequate staff training \\
\hline
\end{tabular}




\section{Annex 6. \\ Some Positive and Negative Aspects of Regional Approaches to Research Coordination}

\begin{tabular}{|c|c|}
\hline Positive & Negative \\
\hline \multicolumn{2}{|c|}{ From the National Research System perspective } \\
\hline $\begin{array}{l}\text { 1. Share information, methodologies, } \\
\text { training }\end{array}$ & 1. Competition in some domains \\
\hline 2. Increase political commitment & $\begin{array}{l}\text { 2. Free-riding (national systems benefiting } \\
\text { without contributing) }\end{array}$ \\
\hline 3. Attract special funding & 3. High costs of participation for small NARS \\
\hline $\begin{array}{l}\text { 4. Increase national exposure for } \\
\text { national systems and scientists }\end{array}$ & $\begin{array}{l}\text { 4. Decisions likely to be taken for political } \\
\text { rather than technical reasons }\end{array}$ \\
\hline 5. Help develop less well-off NARS & 5. Dominance of strongest member(s) \\
\hline $\begin{array}{l}\text { 6. Promote research which otherwise } \\
\text { may not be attempted }\end{array}$ & $\begin{array}{l}\text { 6. Inadequate follow-up of regional initiatives } \\
\text { at the national level }\end{array}$ \\
\hline $\begin{array}{l}\text { 7. Benefit from experiences of other } \\
\text { NARS }\end{array}$ & $\begin{array}{l}\text { 7. Diversion of research effort from NARS } \\
\text { research priorities }\end{array}$ \\
\hline
\end{tabular}

From the perspective of regional organisations

1. Better coordination - among

1. Slowness in bringing about action researchers and institutions

$\begin{array}{ll}\text { 2. Improved donor contacts/negotiations } & \text { 2. Generation of rules and bureaucracy }\end{array}$ Changed attitudes of some members(e.g., towards training)

3. Common services - information, evaluation

3. Risk of territoriality or 'turf' concerns impeding rational decisions

4. Establishment of consultative processes

From the donor perspective

1. Increased awareness of specific issues

1. Reduction of investment in overall strengthening of NARS

2. Promotion/implementation of new approaches

2. Hazy links to national plans

3. Increased efficiency in use of

3. Proliferation of networks resources

4. Better coordination

5. Possibility of bringing in new partners

4. Limited possibility of making long-term commitments (continuity)

6. Demand-led, problem-focused research possible

From the perspective of international research organisations

1. Better priority identification

2. Greater stability/flexibility than other actors

3. Possibility of decentralisation

4. Possibility for incorporation of related research activities and findings

5. Capacity building through research a possibility

6. Peer group pressure between NARS centres helps push progress in research
1. Pressure from donors to administer projects instead of NARS

2. Possible 'turf' syndrome

3. Danger of substitution for technical work of NARS 